\title{
Viscoelasticity and Ultrastructure in Coagulation and Inflammation: Two Diverse Techniques, One Conclusion
}

Albe C. Swanepoel 1,*

Phone +27-12-3192907

Email albe.swanepoel@up.ac.za

Vance G. Nielsen 2

Etheresia Pretorius 1,*

Phone +27-12-3192907

Email resia.pretorius@up.ac.za

1 Department of Physiology, School of Medicine, Faculty of Health Sciences, University of Pretoria, Private Bag x323, Arcadia, 0007 South Africa

2 The Department of Anaesthesiology, The University of Arizona College of Medicine, Tucson, AZ, USA

\section{Abstract}

The process of blood clotting has been studied for centuries. A synopsis of current knowledge pertaining to haemostasis and the blood components, including platelets and fibrin networks which are closely involved in coagulation, are discussed. Special emphasis is placed on tissue factor (TF), calcium and thrombin since these components have been implicated in both the coagulation process and inflammation. Analysis of platelets and fibrin morphology indicate that calcium, tissue factor and thrombin at concentrations used during viscoelastic analysis (with thromboelastography or TEG) bring about alterations in platelet and fibrin network ultrastructure, which is similar to that seen in inflammation. Scanning electron microscopy indicated that, when investigating platelet structure in disease, addition of $\mathrm{TF}$, calcium or thrombin will mask disease-induced alterations associated with platelet activation. Therefore, washed platelets without any additives is preferred for morphological analysis. Furthermore, morphological and 
viscoelastic analysis confirmed that thrombin activation is the preferred method of fibrin activation when investigating fibrin network ultrastructure.

\section{KEY WORDS}

inflammation

coagulation

fibrinogen/fibrin

platelets

morphology

\section{INTRODUCTION}

Coagulation or thrombogenesis is a fundamental part of haemostasis, and the process is well known and biochemically well established. The characteristics of coagulation during pathophysiology is also biochemically well characterised. Particularly, the changes of the coagulation process during inflammation that results in activation of the coagulation cascade, due to tissue factor-mediated thrombin generation, downregulation of physiological anti-coagulant mechanisms and inhibition of fibrinolysis, has been widely studied from a biochemical point of view. Although the biochemical avenues give us great insights into these processes, there are other, albeit neglected, methodologies, including ultrastructural methodologies, e.g. scanning ultramicroscopy, that might give additional as well as complimentary information that might, in addition to confirmatory research, also provide novel insights into the coagulation as well as the processes that govern inflammation. The aim of this review is to evaluate literature concerning coagulation and inflammation and how two diverse techniques, namely, thromboelastography and scanning electron microscopy, can be used in conjunction to determine the interaction between the two mentioned processes. Following the technique described by Gasparyan et al. [1], a comprehensive search through MEDLINE, EMBASE, Scopus and Web of Science was performed using the following keywords: haemostasis, models of coagulation, platelets, fibrinogen, fibrin, tissue factor, calcium, thrombin, blood clotting and inflammation. Articles published in the last 10 years were given preference, although older articles were also included. Therefore, in the current manuscript, we will discuss the intricate relationship between inflammation and coagulation and demonstrate this intricate relationship using morphology and ultrastructure. Several factors associated with coagulation, 
including tissue factor (TF), calcium and thrombin also has an effect on inflammation. We review these factors and their function in platelet activation and creating a fibrin net. Figure 1 shows the layout of this manuscript.

\section{Fig. 1}

An overview figure summarizing the contents of this manuscript.

AQ2

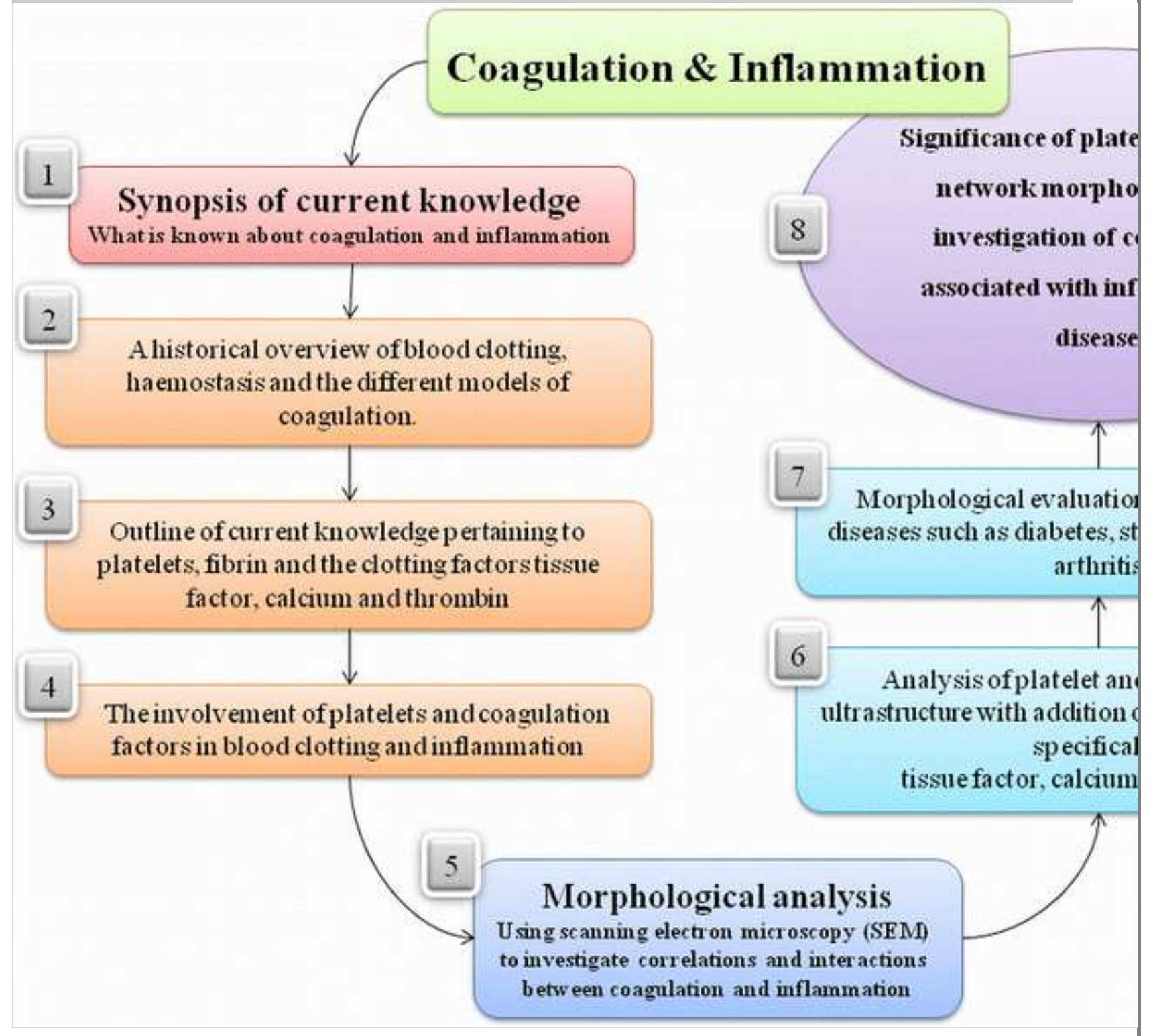

\section{SYNOPSIS OF CURRENT KNOWLEDGE}

\section{Historical Knowledge}

The study of blood clotting is not a new concept. Around $400 \mathrm{BC}$, the father of medicine, Hippocrates, observed that blood congealed as it cooled. He also noted that a small wound would stop bleeding as skin covered the injury area, and, if the skin was removed, the bleeding would resume. Aristotle also 
confirmed that, when blood was removed from the body and cooled, it resulted in the congealing of blood. He was the first to note that, if fibers were removed from the blood, no clotting would occur [2]. The curiosity concerning blood coagulation did not stop with these two masters. Others followed suit and tried to explain their different observations. It was only in the nineteenth century that the theoretical model of blood coagulation was confirmed with sound experimental proof $[2,3]$.

Investigation of platelets only commenced in the nineteenth century upon the first observation by Max Schultze in 1865. He recommended these "normal constituents of blood" as an area of further in-depth study [4]. The Italian pathologist Giulio Bizzozero rose to the challenge. It was only in 1882 that he used microscopy to differentiated platelets from other blood cells. $\mathrm{He}$ continued to describe their function in flowing conditions and the connection between platelet adhesion and aggregation with fibrin formation and accumulation [5].

These discoveries were just the beginning. Ever since, researchers have investigated and come to understand the specific roles of fibrin and platelets in haemostasis.

\section{Haemostasis}

The defence mechanism of the body against exsanguination has two important parts, namely platelet-mediated primary haemostasis and blood coagulation. Upon vessel injury, platelets are responsible for forming a primary haemostatic plug to occlude the injury site [6]. Primary haemostatic plug formation is triggered when platelets adhere to exposed subendothelium of the damaged vascular endothelium. The coagulation cascade is subsequently activated resulting in the production of fibrin. Cross-links between fibrin strands lead to the formation of a network that covers the platelet plug. It seals the injury site and forms the stable, secondary haemostatic plug [7].

Blood loss can be stemmed within seconds owing to the instantaneous and explosive activation of the haemostatic system. This potent system therefore needs to be carefully regulated to ensure that clot formation is not augmented or propagated, which can result in thrombotic complications. Several anti-coagulant factors are set in place to prevent pathological clotting [7].

Antithrombotic properties of the healthy endothelial surface prevent clotting in undamaged vessels. Vessel damage exposes TF, which activates the 
coagulation system, and within seconds, fibrin is produced at the injury site [7]. Rapid activation of the haemostatic system is due to the specific interactions of coagulation factors. The series of reactions where proteolytic cleavage results in the activation of inactive zymogens and cofactors are appropriately referred to as the coagulation cascade. Along with this pro-coagulant process of fibrin formation, the fibrinolytic system is also triggered to ensure that fibrin deposition is limited to the injury site. In addition, the anti-coagulant system ensures negative feedback to the coagulation cascade to block any further activation of the system [7].

The intricacy and numerous factors involved have made the explanation of coagulation complex. Researchers have thus tried to simplify the process by using different models to explain the process of coagulation.

\section{Models of Coagulation}

In 1964, both Davie and Ratnoff, as well as MacFarlane, proposed the "cascade" or "waterfall" models of coagulation [ 8,9$]$. This was a great improvement on the concept of the coagulation process. In 1994-1996, the possibility of a cell-based model for haemostasis was introduced [10-12]. It is thought to be a better explanation of haemostasis than the traditional "cascade" or "waterfall" hypothesis since the intrinsic and extrinsic coagulation pathways are linked almost from the beginning of the coagulation process. Coagulation is also thought to be not a continuous process but rather a process that requires consecutive phases [13].

Three overlapping phases are proposed, namely the initiation phase, followed by the amplification phase and ending with propagation phase. Platelets and thrombin are both intricately involved in the last two phases [13-15]. In the first phase, the initial phase, the interaction between and factor VII activates factor X. This occurs directly or indirectly through the action of factor IX. Small amounts of prothrombin are transformed to thrombin. However, this concentration of thrombin is insufficient for the completion of fibrin fiber formation [13-15].

During the second phase, the amplification phase, the thrombin produced along with calcium form the blood and platelet-derived acidic phospholipids activates factors XI, IX, VIII and V in a positive feedback process. Platelet activation is accelerated by chemotactic attraction of the mentioned factors to the surface of the platelets, amplifying the process [13-15]. 
The last phase, the propagation phase, involves the feedback mechanism that thrombin, platelets and the activated factors exhibit. Large quantities of prothrombin are converted to thrombin to drive the formation of fibrin. This final process, which occurs mainly on the surface of platelets, results in the explosive generation of large quantities of thrombin and fibrin [13-15]. Calcium acts as an allosteric effector to induce activation of factor XIII, which facilitates the cross-linking of the formed fibrin fibers to form a network [16]. Factor XIII is found in the plasma, but it can also be stored in platelets as well as monocytes and macrophages [17]. The generation of factor XIII is orchestrated in such a way that the foregoing thrombin-mediated activation of fibrin and subsequent cross-linking will only proceed effectively after fibrinopeptide $\mathrm{A}$ is removed to form fibrinogen, thus initiating the clotting process [18].

The importance of cellular control during coagulation and the process of haemostasis in vivo are better explained in this manner. This model also assists in understanding the pathophysiological mechanisms involved in certain coagulation disorders [19]. A model is a method by which a complicated system is conceptualised and understood. A good model should be simplistic and fundamental for better understanding but also intricate and complex to accurately display the process it was intended to convey [20].

Although a cell-based model has recently been deemed a more comprehensive description of coagulation in the body than the cell-free cascade models [21], this review will apply both the older cell-free model (showing the intrinsic, extrinsic and common pathway) as a simplified method to explain the involvement of TF, thrombin and calcium in the coagulation process as well as the more modern cell-based model to explain platelet involvement in blood clotting.

The vast amount of literature pertaining to the coagulation cascade model, including the factors involved, specific interaction and the regulation of the system amongst others, has been well-documented [6-8, 13, 14, 22-55]. Figure 2 represents a summary of the factors involved in the coagulation cascade, with particular emphasis on the influence of TF, thrombin and calcium on the system. Figure 3 shows the cell-based model and the involvement of TF, thrombin and calcium on platelets during blood clotting. 
Fig. 2

Outline of cascade/waterfall model of coagulation.

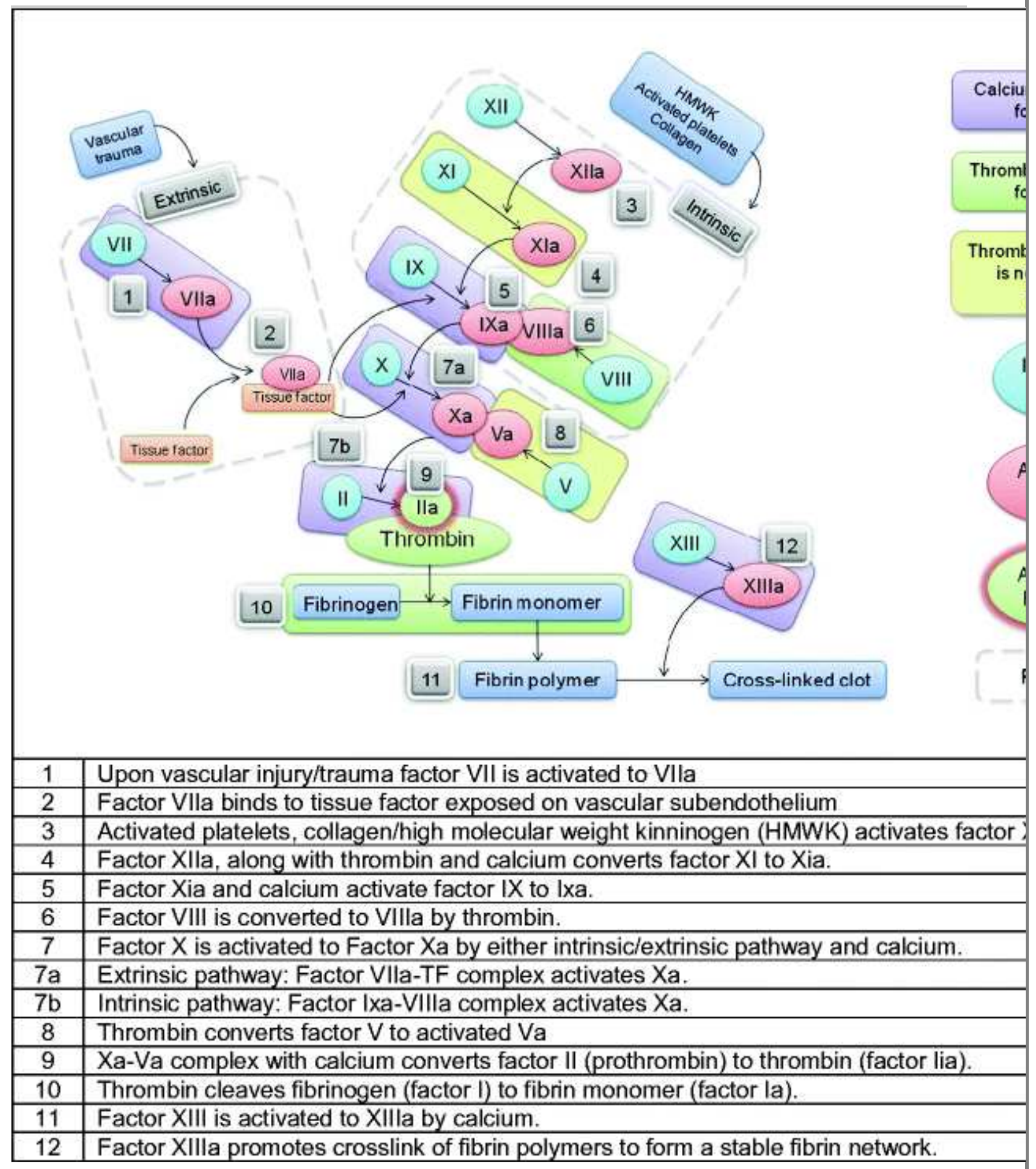

Fig. 3

Outline of cell-based model of coagulation. 


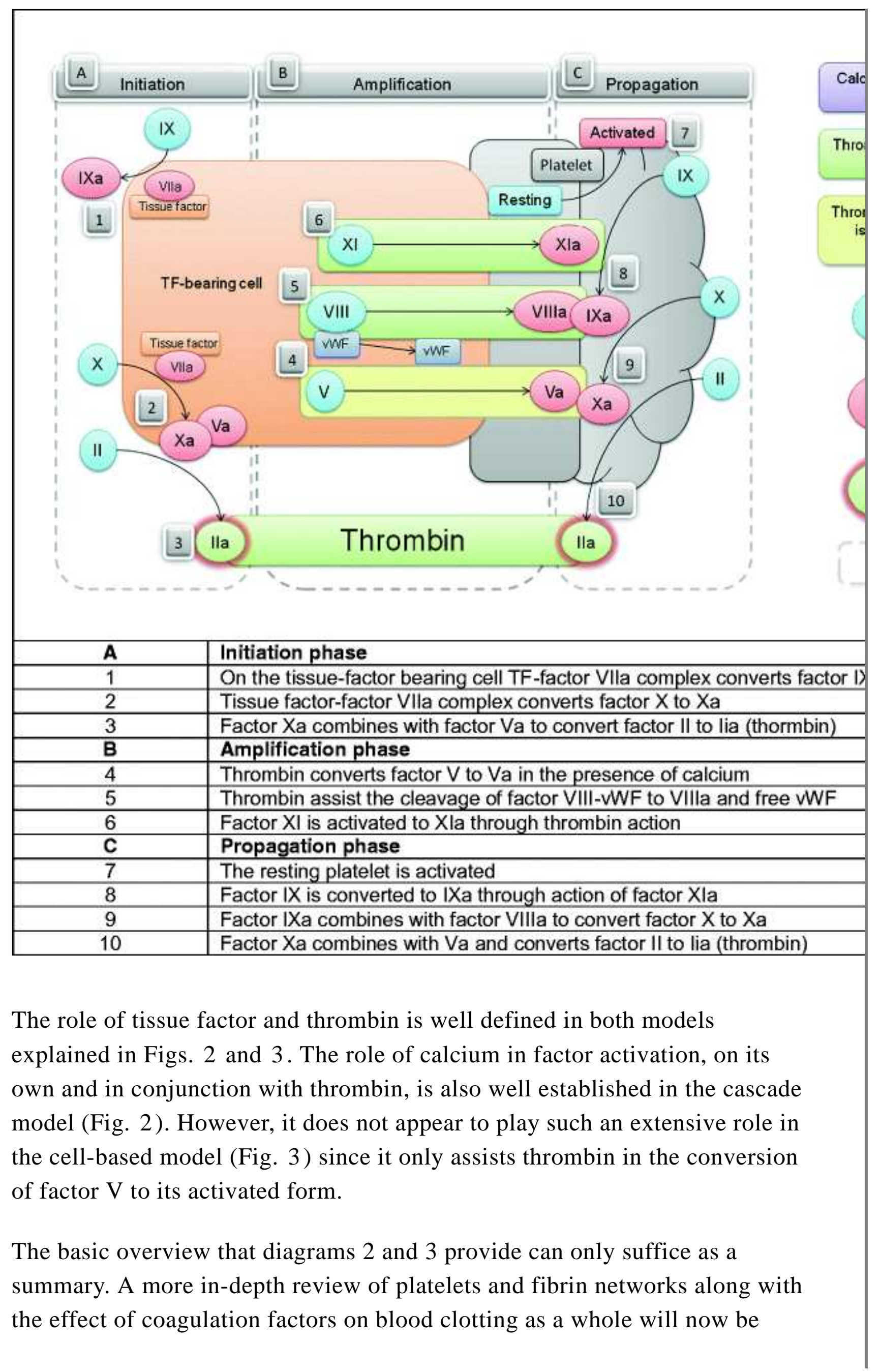




\section{PLATELETS, FIBRIN NETWORKS AND CLOTTING FACTORS}

\section{Platelets}

Bone marrow megakaryocytes give rise to small fragments called platelets.

Within these non-nucleated cells, a few mitochondria, glycogen and a complex membranous system can be differentiated along with three types of morphologically different granules. The $\alpha$-granules, dense granules and lysosomes, each contain their own unique constituents essential for blood clotting. Table 1 gives a summary of these constituents and their functions [56-58].

\section{Table 1}

Platelet Granules and Their Constituents

\begin{tabular}{|c|c|c|c|}
\hline \multirow{4}{*}{$\alpha$-granules } & $\begin{array}{l}\text { Adhesion } \\
\text { molecules }\end{array}$ & $\begin{array}{l}\text { P-selectin } \\
\text { vWF } \\
\text { Thrombospondin-1 } \\
\text { Fibronectin } \\
\text { PF-4 }\end{array}$ & $\begin{array}{l}\text { Platelet-platelet } \\
\text { interaction } \\
\text { Platelet interactions with } \\
\text { other blood cells }\end{array}$ \\
\hline & $\begin{array}{l}\text { Mitogenic } \\
\text { factors }\end{array}$ & PDGF & $\begin{array}{l}\text { Cell growth and cell } \\
\text { division }\end{array}$ \\
\hline & $\begin{array}{l}\text { Coagulation } \\
\text { factors }\end{array}$ & $\begin{array}{l}\text { Fibrinogen } \\
\text { Plasminogen } \\
\text { Factors V, VII, XI, } \\
\text { XIII }\end{array}$ & Coagulation \\
\hline & $\begin{array}{l}\text { Protease } \\
\text { inhibitors }\end{array}$ & $\begin{array}{l}\text { PAI-1 } \\
\text { TAFI }\end{array}$ & Fibrinolysis \\
\hline \multirow{3}{*}{$\begin{array}{l}\text { Dense } \\
\text { granules }\end{array}$} & Nucleotides & $\begin{array}{l}\text { ADP and ATP } \\
\text { GDP and GTP }\end{array}$ & \multirow{3}{*}{$\begin{array}{l}\text { Amplification of platelet } \\
\text { aggregation } \\
\text { Modulation of vascular } \\
\text { endothelium and } \\
\text { leukocyte function }\end{array}$} \\
\hline & Amines & $\begin{array}{l}\text { Serotonin } \\
\text { Histamine }\end{array}$ & \\
\hline & $\begin{array}{l}\text { Bivalent } \\
\text { cations }\end{array}$ & $\begin{array}{l}\mathrm{Ca}^{2+} \\
\mathrm{Mg}^{2+}\end{array}$ & \\
\hline Lysosomes & $\begin{array}{l}\text { Hydrolytic } \\
\text { enzymes }\end{array}$ & $\begin{array}{l}\text { Glycosidase } \\
\text { Proteases }\end{array}$ & $\begin{array}{l}\text { Digest material in } \\
\text { platelet aggregates } \\
\text { through hydrolytic }\end{array}$ \\
\hline
\end{tabular}

$v W F$ von Willebrand factor, $P F-4$ platelet factor-4, $P D G F$ platelet-derived growth factor $P A I-1$ plasminogen activator inhibitor-1, TFPI thrombin activatable fibrinolysis inhibitor, $A D P$ adenosine diphosphate, $A T P$ adenosine triphosphate, $G D P$ guanosine diphosphate, GTP guanosine triphosphate, $\mathrm{Ca}^{2+}$ calcium ions, $M g^{2+}$ magnesium ions 


\begin{tabular}{l|l|l} 
Proteins & Cationic proteins & Bactericidal activity
\end{tabular}

$v W F$ von Willebrand factor, $P F-4$ platelet factor-4, $P D G F$ platelet-derived growth factor PAI-1 plasminogen activator inhibitor-1, TFPI thrombin activatable fibrinolysis inhibitor, $A D P$ adenosine diphosphate, $A T P$ adenosine triphosphate, $G D P$ guanosine diphosphate, GTP guanosine triphosphate, $\mathrm{Ca}^{2+}$ calcium ions, $M g^{2+}$ magnesium ions

Platelets circulate in a quiescent state until injury to the endothelium triggers platelet activation and subsequent interaction of the activated platelets with neutrophils and monocytes $[59,60]$. After platelet activation, they adhere to the site of injury and aggregate to form a platelet plug, also referred to as the primary haemostatic plug. This reduces and temporarily stems blood loss at the injury site. Platelet activation also causes platelet degranulation, where various proteins and molecules (the constituents listed in Table 1) are released that recruit additional platelets and assists in the process of tissue repair [61].

Plasma proteins, especially von Willebrand factor, are essential for platelet adhesion. Von Willebrand factor acts as a bridge between the platelets and the injury site $[62,63]$ as it binds to specific receptors, namely glycogprotein $\mathrm{Ib} /$ glycoprotein IX, on the surface of activated platelets as well as the subendothelium [64]. Similarly, fibrinogen also acts a platelet-platelet bridge as it binds to the surface receptors glycoprotein IIb/IIIa on adjoining activated platelets $[65,66]$.

This linking of activated platelets results in platelet aggregation and subsequent platelet plug formation. These "bridge reactions" causes the exposure of phosphatidylserine, negatively charged phospholipids, on the activated platelet surface and damaged cell membrane. Fibrin formation is triggered, and insoluble fibrin strands form a clot that reinforces the platelet plug [8].

Thrombin-induced activation of platelets initiates degranulation, adhesion and aggregation of platelets resulting in thrombus formation [67].

It is the increase in cytoplasmic $\mathrm{Ca}^{2+}$ concentration that drives all the abovementioned functions [68, 69].

Platelets are thus essential for the formation of the primary haemostatic plug, 
a vital part of the initial stent of blood. Subsequently, a fibrin network needs to be produced to create the stable, secondary haemostatic plug essential for wound healing.

\section{Fibrinogen and Fibrin}

Fibrin formation marks the final step of blood coagulation. Fibrin strands act as a plug to seal the injury site and thus protects the damaged tissue while the wound heals [7]. A number of steps are involved in this closely controlled process of fibrin formation. The expansion and strength of a blood clot depends on the conversion of fibrinogen to fibrin. This is accomplished by the enzymatic action of thrombin. Fibrinogen, a large centrosymmetric glycoprotein with a high molecular mass of around $330 \mathrm{kDa}$, is a trinodular structure found in elevated levels of about $9 \mathrm{mM}$ in the plasma [70, 71]. Fibrin monomers contain three pairs of polypeptide chains, referred to as the $\mathrm{A} \alpha, \mathrm{B} \beta$ and $\gamma$ polypeptides, which are curved into a central $\mathrm{E}$ region with two distal D regions [72, 73].

The serine protease thrombin, formed on activated and adhering platelets at an injury site, cleaves fibrinogen molecules to yield the fibrin monomers fibrinopeptides A and B [70, 72]. Fibrinopeptide A serves as an early detection marker for fibrinogen-to-fibrin conversion [45].

Fibrinopeptide cleavage results in "hole" formations. Corresponding "knobs" fit into the "holes", and in this way, fibrin monomers can assemble. The assembly of fibrin monomers has a half-staggered configuration and together form protofibrils. As the bundle protofibrils aggregate laterally, they form fibrin fibers. An insoluble fibrin gel is formed when the fibrin strands aggregate and form cross-links through the actions of thrombin-catalysed factor XIIIa [49, 70, 74, 75].

While soluble fibrinogen essentially forms part of the coagulation system, it contributes to various other cellular processes. It operates as a signalling molecule and plays and essential role in the adhesion process necessary for transferring immune cells in the process of wound healing [76]. Along with fibrin, it also enhances angiogenesis, therefore stimulating tumour growth [50].

The fibrin fiber network is considered to be an intricate, hierarchical biomaterial [77, 78]. Fibrin gels are considered as one of the most resilient natural polymers, since it can withstand strain (being shear or tensile) of up to 
$300 \%[79,80]$. Upon deformation, fibrin gels become rigid and congeal. It is through this process that they become increasingly resistant to any further deformation [81-86].

Fibrin networks have also been shown to exhibit a unique set of mechanical properties such as extraordinary extensibility, non-linear elasticity or strain stiffening and negative normal stress [74, 78-83, 86-95]. The main focus of fibrin behaviour has been on macroscopic level. Only recently investigation into the molecular and fiber-level origins has come to the foreground [ 80,82 , $83,92,96]$.

Thrombin is necessary for haemostatic clot formation since it converts fibrinogen to fibrin [97]. Thrombin concentration is particularly important since it influences both the thickness of the fibers as well as the density of the fibrin clot [98]. Thrombin, therefore, plays a vital role in blood clotting.

\section{Tissue Factor}

$\mathrm{TF}$ is an integral membrane protein found in the blood vessel wall. It primarily initiates physiological coagulation and can trigger arterial and venous thrombosis [99]. As TF binds to activated factor VII (VIIa), this enzymatically active complex transforms factors IX and $\mathrm{X}$ to their active forms (IXa and Xa, respectively) to trigger clot formation by means of thrombin generation [100].

TF have been identified in the platelet membrane as well as the matrix of platelet $\alpha$-granules. The stored TF is exposed on the surface of activated platelets [99].

Calcium is needed for the conversion of factor IX to IXa as well as X to Xa. $\mathrm{TF}$ and calcium are, therefore, equally important for clot formation.

\section{Calcium}

Platelet function greatly depends on calcium ions. GP IIb/IIIa is a receptor for fibrinogen supports both platelet aggregation and adhesion [101, 102]. This integrin complex has a great affinity for binding to calcium ion $\left(\mathrm{Ca}^{2+}\right)$ at its five divalent cation binding sites [103, 104]. Platelet activation has been shown to increase the signalling of platelet $\mathrm{Ca}^{2+}[105]$. Calcium is essential for the conversion of several coagulation factors from their zymogen form to their activated state, including factor XIII. Activated factor XIII forms an 
integral part of normal blood coagulation since it catalyses the formation of covalent bridges between fibrin units resulting in increased elasticity of the fibrin network. Although thrombin and calcium have both been implicated in the activation of factor XIII, thrombin is only responsible for limited proteolysis, while calcium plays an essential role by unmasking buried cysteine essential for fibrin cross-linking [106-108].

It facilitates the conversion of factor VII to factor VIIa [109-111], factor VIII to VIIIa [112], factor IX to IXa [113] and factor XIII to XIIIa [114, $115]$. In the final steps of the coagulation pathway, two essential complexes are formed, namely the tenase complex and the prothrombinase complex. In the tenase complex, activated factor IX (Ixa) binds to factor VIIIa to activate factor $\mathrm{X}$ to $\mathrm{Xa}$. In the prothrombinase complex, activated factor X (Xa) binds to factor Va to convert prothrombin to thrombin. Calcium plays an integral role in the activation of both these complexes, which ultimately lead to the production of thrombin [7].

Calcium also plays a role in anti-coagulant action. In the presence of calcium, both factor Va [116, 117] and factor VIIIa [118] can be inactivated through the action of the vitamin K-dependent protein C and protein S [119].

\section{Thrombin}

Thrombin is deemed the one of the important coagulation factors given that its action is central to clot formation. It is the final protease generated in blood coagulation upon activation of several coagulation factors [120]. Thrombin generation at injury sites in the vascular system results from a well-organised series of reactions collectively referred to as blood coagulation [8, 22, 23]. The protease thrombin has to be under strict regulation to ensure that blood clotting is not augmented to uncontrolled thrombosis [121].

Thrombin has three main functions in the blood clotting process. Firstly, it is responsible for platelet activation. Thrombin is regarded as the most potent platelet agonist [122]. This is best explained by referring to the cell-based coagulation model (figure Y). Secondly, it is involved in the formation of fibrin. Fibrinogen is cleaved by thrombin to generate fibrin, as explained earlier. Lastly, thrombin is associated with the amplification of the coagulation feedback system. In the propagation phase of the cell-based model, the positive feedback from thrombin along with the activated platelets and coagulation factors results in the amplification of the prothrombin 
conversion to thrombin and ultimately fibrin formation.

Thrombosis, the over-activation of the blood coagulation system that causes blood clots, which can ultimately lead to occlusion of blood vessels, is caused by over-generation of thrombin [52]. Tight regulation of thrombin generations, therefore, needs to be maintained to ensure normal blood flow.

Thrombin formation is dependent on the presence of calcium. Calcium serves as a cofactor for platelet activation and ultimately the formation of fibrin.

Platelets and fibrin along with certain factors of coagulation, therefore, play an essential role in normal blood clotting. These factors are also involved in inflammation.

\section{BLOOD CLOTTING AND INFLAMMATION}

As mentioned in the introductory paragraphs, there are a fundamental correlation between the inflammatory process and the coagulation cascade. The interactions are demonstrated in Fig. 4.

Fig. 4

Overview of correlations between inflammation and coagulation. 


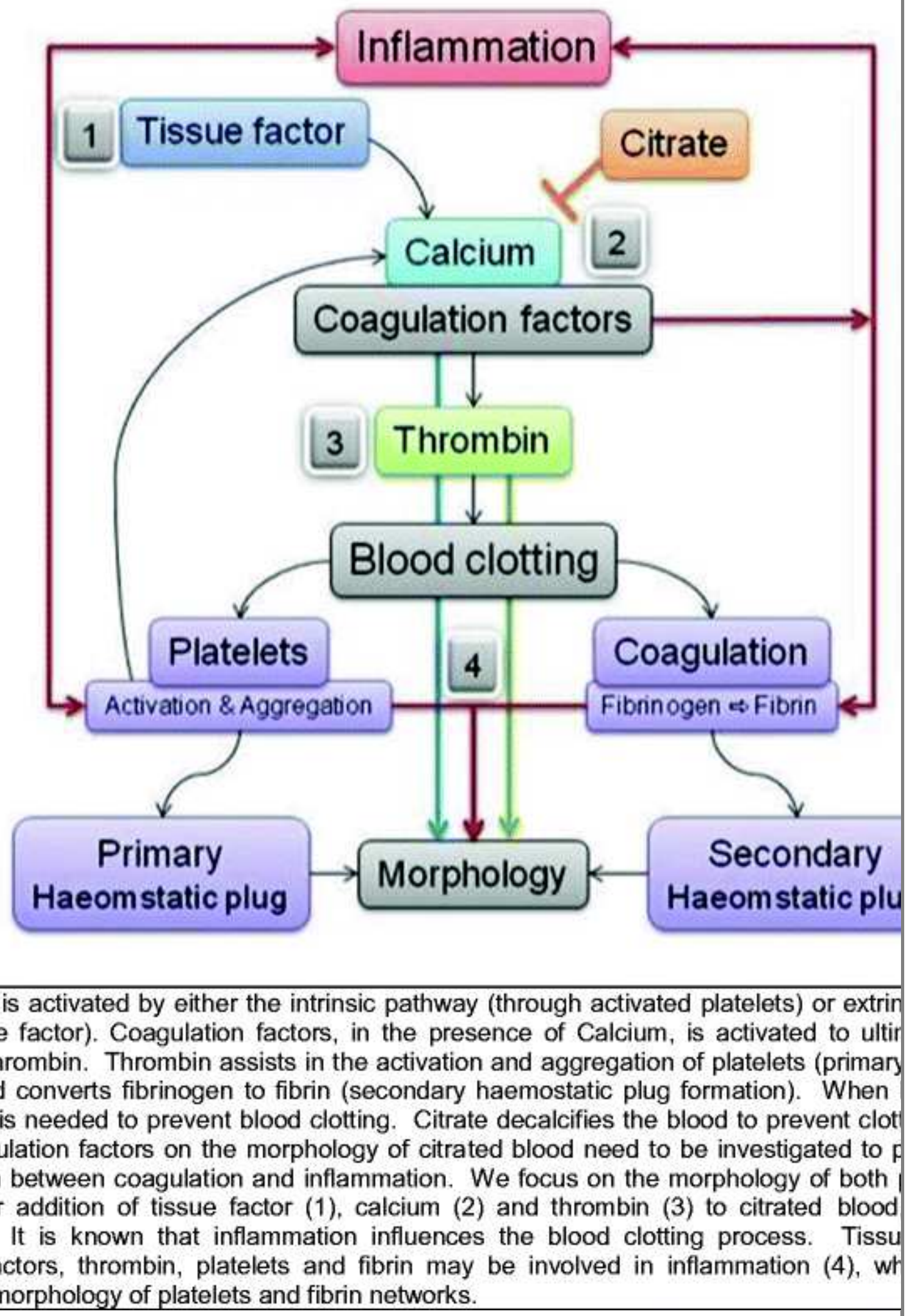

The blood clotting process is set in motion either through the intrinsic or extrinsic pathway. The former is triggered mainly by platelet activation, while the latter is initiated by the exposure of tissue factor due to vascular trauma. Activation of coagulation factors, which ultimately result in thrombin production, requires calcium for their activation. Thrombin has a dual action in haemostasis; it assists in primary haemostatic plug formation by supporting 
platelet activation and aggregation, while, through conversion of fibrinogen to fibrin, it assists secondary plug formation leading to a stable fibrin network. The anti-coagulant citrate is used in phlebotomy to effectively prevent blood clotting by decalcifying the drawn blood. Morphological analysis is a good approach to investigate coagulation factors and the correlation between coagulation and inflammation.

The focus of this section is to investigate the effect of tissue factor, calcium and thrombin on the platelets and fibrin network ultrastructure. By investigating the effects of the mentioned factors, individually or in combination with each other, on citrated blood will unlock supplementary information pertaining to blood clotting. Since a close correlation exist between inflammation and coagulation, the involvement of TF, calcium and thrombin in coagulation may correspond to inflammation. Both these processes may thus have a similar influence on platelet and fibrin network morphology owing to the mentioned coagulation factors.

Damage to tissue and cells can be cause by physical injury, infective pathogens or chemicals and other noxious stimuli. The body's immediate response to repair and protect is referred to as inflammation [123, 124]. Tissue injury results in acute phase inflammation. It is considered a short-term response associated with healing facilitated by increased blood flow along with vascular permeability accompanied by leukocyte infiltration to remove the stimulus and subsequent tissue repair [123-125] In contrast, a chronic inflammatory response is a drawn out and dysregulated process that is maladaptive in nature. It is also referred to as a subacute inflammatory response and involves specific immune responses to the pathogens present at a tissue injury site [123-125]. Both humeral and cellular factors are activated in this multifactoral defensive process [126]. Active inflammation is accompanied by tissue destruction associated with insufficient tissue repair. Several chronic diseases are associated with this persistent inflammatory process including atherosclerosis and cancer [123, 124].

Inflammation is able to bring about thrombosis, and thrombosis in turn is capable of amplifying the inflammatory response [127].

\section{Platelets}

Platelets form part of haemostasis, wound healing and inflammation [59, 60]. For an up-to-date summary of platelets in inflammation and thrombosis, 
specifically in atherosclerosis, see Gasparyan [128].

Mean platelet volume (MPV) has been implicated as the link between inflammation and thrombosis, since high MPV is associated with both low-grade inflammatory conditions as well as an increased risk for thrombosis [129]. The use of MPV has also been suggested in monitoring anti-inflammatory treatment of high-grade inflammatory diseases, predominantly rheumatoid arthritis [130, 131].

Platelets have been shown to decisively influence the pathogenesis of numerous inflammatory diseases, vascular inflammation and atherogenesis in particular [132, 133].

Hyperactive platelets play a pivotal role in the link between inflammation and coagulation as it can trigger local rheumatoid inflammation along with their interaction with other cells to target the vascular wall [134].

The inflammatory response has an effect on platelet reaction. Platelet production is increased by certain inflammatory mediators, like interleukin (IL)-6. These platelets are more thrombogenic and show a greater thrombin sensitivity [135].

Platelets also influence the inflammatory process. Elevated levels of the proinflammatory-mediator CD40 ligand are contained within platelets. CD40 ligand is released upon platelet activation. CD40 ligand not only induces the synthesis of TF [136, 137] but also amplifies inflammatory cytokine production, including IL-6 and IL-8 [138, 139]. Platelet secretion of chemokines and IL-1 initiates white cell activation and advance the adherence of neutrophils and monocytes [140]. P-selectin expressed on activated platelets increase neutrophil-platelet-endothelial cell interactions [141]. Platelet P-selectin, expressed as platelets adhere to the subendothelial matrix, interacts with P-selectin glycoprotein ligand-1 expressed on leukocytes. This promotes the rolling, adhesion and transmigration of leukocytes at the injury site [142].

Platelets are also considered important amplifiers of acute inflammation through their particular interaction with neutrophils. This platelet-neutrophil interaction promotes the recruitment of additional neutrophils into inflammatory tissue. In adhering to damaged endothelial cells and monocytes, platelet also promotes the secondary capture of neutrophils and other 
leukocytes while it also secretes activators indirectly responsible for inflammatory cytokine production [56].

Recently, it has been found that platelets do not only display pro-inflammatory properties. A single platelet receptor, platelet GP Ib-IX, can have a modulatory role in both the coagulation system and inflammatory response. It can be regard as a multifunctional contributor in haemostasis, thrombosis and inflammation. This emphasises the dynamic function of platelets in systemic inflammation [143].

A variety of soluble factors are involved in both acute and chronic phase inflammation. These factors increase the expression of cellular adhesion molecules and assist in chemoattraction to recruit leukocytes to the target area [125].

\section{Pro-coagulants}

Both coagulation and inflammation are instrumental for the identification, containment and destruction of invading pathogens and also restriction of the amount of tissue damage [144]. The inflammatory processes are closely associated with a number of blood coagulation factors [145]. When the innate immune response is activated by any infectious agent, blood coagulation is subsequently triggered [141]. Constituents of the blood coagulation process can influence inflammation in a constructive or destructive way by either amplifying or inhibiting the inflammatory processes $[52,146]$.

It is, therefore, impossible to consider inflammation and coagulation as two separate processes. The inflammatory response initiates the activation of the coagulation system, and coagulation significantly influences the activity of the inflammatory process. Points of extensive cross-talk, therefore, exist between these two systems [147].

Several articles explain the different aspects of the interplay between inflammation and coagulation [126, 141, 144, 147-157]. The following is a basic overview of where these two processes overlap.

The first point of overlap is the endothelium. Exposed surface proteins from damaged endothelium serve as a trigger for both the coagulation process as well as the inflammatory response. Cytokines released during inflammation is the second point of overlap. Cytokines released during the inflammatory process downregulate thrombomodulin expression and protein $\mathrm{C}$ activation 
while upregulating TF expression. In this way, inflammation modulate the coagulation system by altering pro-coagulant and anti-coagulant equilibrium. The third point of overlap is the production of thrombin by the coagulation cascade. It is well known that thrombin plays a vital role in promoting haemostasis. It also involved in the stimulation of various cell functions such as chemotaxis and mitogenesis. Both these processes are involved in lesion spreading and the process of tissue repair.

\section{Anti-coagulants}

Three major anti-coagulant pathways regulate the activation of the coagulation process. These include antithrombin, protein $\mathrm{C}$ pathway and $\mathrm{TF}$ pathway inhibitor (TFPI) [158]. Natural anti-coagulants do not only oppose the coagulation cascade. Firstly, anti-coagulant processes diminish leukocyte chemotaxis [159]. They suppress endothelial-cell interactions [160] as well as apoptosis [161, 162]. Anti-coagulant activity also reduces cytokine expression [163-165]. Therefore, anti-coagulant processes have a diminishing effect on inflammatory activity.

The natural anti-coagulant pathways can, however, be suppressed through inflammation-induced activation of the coagulation system [158] as an acute inflammatory reaction results in the consumption, proteolytic inactivation and downregulation of protein expression [141]. TF, calcium and thrombin, although essential coagulation factors, are also associated with inflammation.

\section{Other Coagulation Factors}

TF expression is upregulated during an inflammatory response and frequently results in a hypercoagulable state [166]. It plays an integral part in the coagulation-inflammation cycle. Coagulation resulting from TF expression provokes intracellular signalling, resulting in the release of coagulant mediators (incuding factors VIIa, Xa and IIa) and subsequent fibrin formation, which have a proinflammatory function. Inflammation in turn can increase the expression of TF, resulting in increased expression of the above-mentioned proinflammatory coagulant mediators and fibrin production. In this way, TF, by sustaining this coagulation-inflammation cycle, will result in an enormous inflammatory response [167].

Calcium salts have been shown to induce biochemical changes similar to changes found in systemic inflammation [168]. Calcium has also been shown to modulate the expression of TF pro-coagulant activity on the cell surface 
Activated thrombin is more than just a fibrin deposition initiator. It also activates a pro-inflammatory response. Thrombin mediates the expression of P-selectin on endothelial cells and platelets. P-selectin is essential for the interactions that ultimately join circulating granulocytes, monocytes and lymphocytes to the endothelium at the injury site [170, 171]. The thrombininduced expression of P-selectin on endothelial cells not only supports white cell adherence but also promotes the cellular activation with capillaries [141]. Thrombin also sustains ongoing coagulation by initiating the production of endothelial IL-6 that promotes the expression of TF [52, 172].

Blood clotting and inflammation are two intertwined processes-they have a distinct effect on each other. Although several biochemical investigations have revealed these interactions, a morphological investigation may shed more light on the subject.

\section{FIBRIN AND PLATELET ANALYSIS}

Citrate is an effective anti-coagulant and is used for blood collection on a regular basis. It prevents blood coagulation through its chelating action on calcium and other metal ions [173]. Citrated blood is a preferred method of investigating blood factors outside the body.

In viscoelastic or thrombelastographic analysis, citrated whole blood is recalcified with calcium chloride $\left(\mathrm{CaCl}_{2}\right)$ to determine clotting times for the extrinsic and intrinsic coagulation pathways as well as the time period of fibrinolysis after clot formation. The effect of different concentrations of TF on coagulation kinetics (initiation, propagation and final clot strength) in human plasma is determined [159]. These analyses demonstrated that an ionised calcium concentration between 1 and $2 \mathrm{mM}$ in the presence of 2000 pM TF was optimal with regard to plateau of time of onset of clotting, velocity of clot formation and maintenance of final clot strength [159]. Thus, this concentration of TF was utilised in subsequently presented scanning electron microscopy (SEM) data and viscoelastic analysis.

Since TF and calcium concentrations are critical modulators of coagulation, with thrombin production as ultimate goal to form fibrin fibers, defining the effect of these modulators on platelet and fibrin network morphology is an important goal when investigating coagulation and inflammation. 


\section{Morphological Analysis}

Citrated blood was used to prepare platelet and fibrin smear for SEM analysis. Blood was centrifuged at $1250 \mathrm{rpm}$ for $10 \mathrm{~min}$. The plasma supernatant was transferred to an Eppendorf tube and centrifuged for a further 4 min at $1250 \mathrm{rpm}$ to obtain the supernatant platelet poor plasma (PPP) as well as the platelet-rich plasma (PRP) pellet. The supernatant PPP in the Eppendorf tube was used to make fibrin smears, while the PRP pellet obtained from centrifugation was washed twice with $0.075 \mathrm{M}$ PBS and used to make plasma smears. Tissue factor and calcium [in the form of calcium chloride $\left(\mathrm{CaCl}_{2}\right)$ ] were added at concentrations used for TEG analysis, namely $2000 \mathrm{pg} / \mathrm{ml}$ and $0.2 \mathrm{M}$, respectively. Samples were incubated for $5 \mathrm{~min}$ at $37^{\circ} \mathrm{C}$. The concentrations and combinations used for the incubation period and subsequent preparation of the smears on glass coverslip are indicated in the table (Table 2). The samples were subsequently prepared for SEM as previously described by Swanepoel and Pretorius [174-176].

\section{Table 2}

Combinations and Concentrations of the Different Components to Which Samples were Exposed (Incubation Period) Prior to Preparation of Smears on Glass Coverslips (Smear Preparation)

\begin{tabular}{|c|c|c|}
\hline & Incubation period & Smear preparation \\
\hline 1 & Nothing added & $\begin{array}{l}\text { a. } 10 \mu l \text { of sample on a glass coverslip (nothing } \\
\text { added) } \\
\text { b. } 10 \mu l \text { of sample }+5 \mu 1 \text { thrombin on a glass } \\
\text { coverslip }\end{array}$ \\
\hline 2 & $\begin{array}{l}340 \mu 1 \text { plasma }+20 \mu l \\
\mathrm{CaCl}_{2}(0.2 \mathrm{M})\end{array}$ & $\begin{array}{l}\text { c. } 10 \mu \mathrm{CaCl}_{2} \text {-sample mixture on a glass } \\
\text { coverslip } \\
\text { d. } 310 \mu \mathrm{C} \mathrm{CaCl}_{2} \text {-sample mixture }+10 \mu \mathrm{l} \text { tissue } \\
\text { factor }(2000 \mathrm{pg} / \mathrm{ml}) \\
\text { i. } 10 \mu \mathrm{l} \mathrm{CaCl} \mathrm{Cl}_{2} \text {-sample-TF mixture on a glass } \\
\text { coverslip } \\
\text { ii. } 10 \mu \mathrm{l} \mathrm{CaCl}{ }_{2} \text {-sample-TF mixture }+5 \mu \mathrm{l} \\
\text { thrombin on a glass coverslip }\end{array}$ \\
\hline
\end{tabular}

\section{Platelets}

Platelets, without the addition of any coagulation factor, appear spherical with pseudopodia and small open canalicular pores on their surface (Fig. 5a). This is typical of healthy or resting platelets.

\section{Fig. 5}

Platelets of healthy controls with addition of certain coagulation factors. a 
Control platelets with no factors added. c Platelets incubated with $0.2 \mathrm{M} \mathrm{CaCl}_{2}$ for 5 min. d Platelets incubated for 5 min with $0.2 \mathrm{M} \mathrm{CaCl}_{2}$, and subsequent addition of 2000pM TF. e Platelets incubated for 5 min with $0.2 \mathrm{M} \mathrm{CaCl}_{2}$, and subsequent exposure to $2000 \mathrm{pM}$ TF and thrombin. f Platelets incubated with $\mathrm{CaCl}_{2}$ for $5 \mathrm{~min}$, and subsequent exposure to thrombin. $\mathrm{g}$ Platelets exposed to thrombin. Scale bar indicates $1 \mu \mathrm{m}$. Large white arrows indicate platelet spreading, large black arrows show membrane blebbing and small white arrows show pseudopodia formation.

AQ3
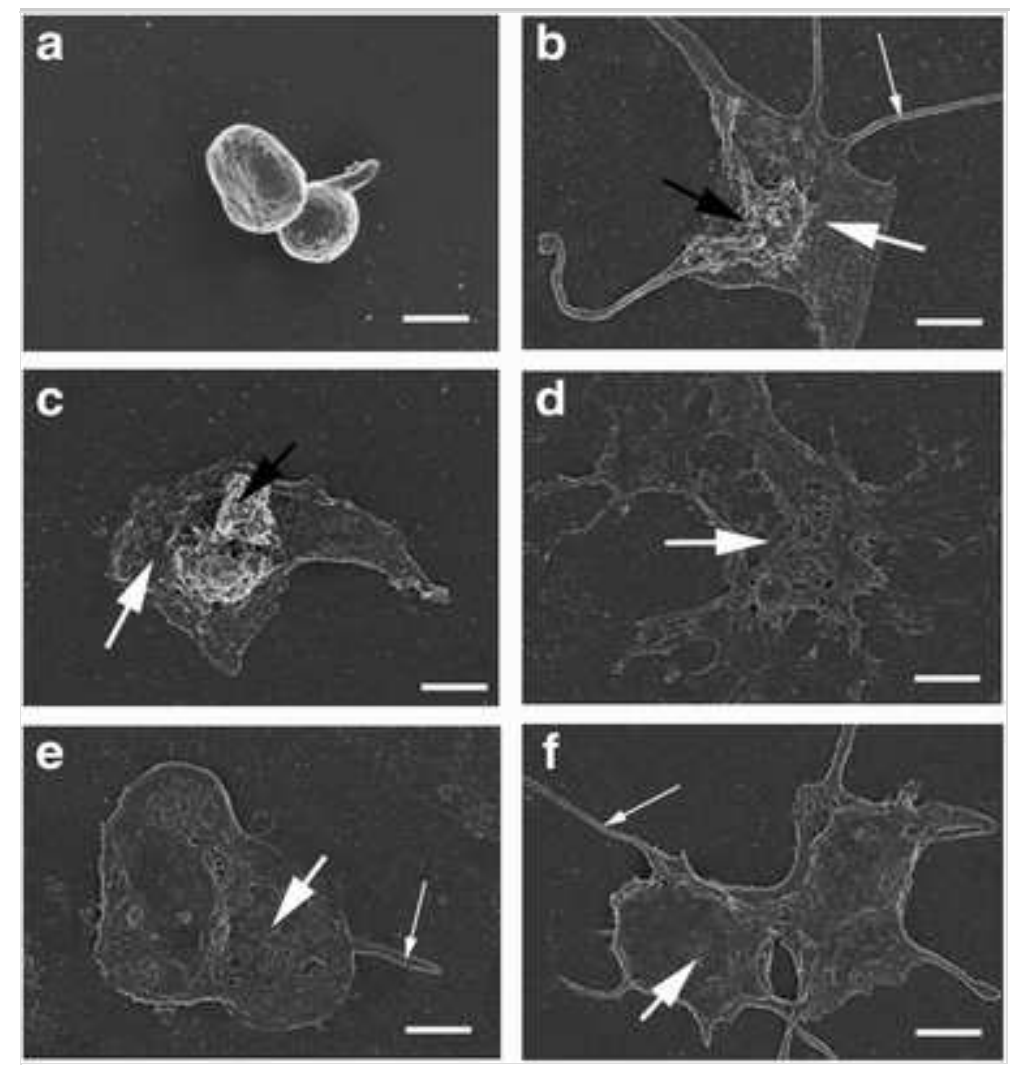

When $\mathrm{CaCl}_{2}$, on its own and in combination with $\mathrm{TF}$ and thrombin, is added as indicated in Table 2, the platelets become activated (as shown in Fig. 5b-f). Platelet activation is morphologically characterised by membrane blebbing (shown with the large black arrows in Fig. 5b and c), platelet spreading (as indicated in presence of all factors and combinations of factors; indicated with the large white arrows in Fig. 5b-f) and extensive pseudopodia formation (in the presence of $\mathrm{CaCl}_{2}$ and thrombin separately; shown with the small white arrows in Fig. 5b, e and f).

These findings indicate that platelets are over-activated by the addition of $\mathrm{CaCl}_{2}$, TF and thrombin. We have come to the conclusion that, when investigating platelet morphology in inflammatory diseases, it is best to use 
washed platelets without any additives. This will provide a clear representation of the pathology associated with the inflammatory condition, without the interference of exogenous stimulation.

\section{Fibrin Networks}

PPP from citrated blood cannot be activated on its own since PPP without coagulation factors only result in the dispersal of plasma droplets (Fig. 6a). When $\mathrm{CaCl}_{2}$ is added to PPP for 5 min, typical fibrin fibers are formed with fibrin fiber deposits in some areas associated with over-activation (Fig. 6b). When PPP, incubated with $\mathrm{CaCl}_{2}$ for $5 \mathrm{~min}$, is subsequently exposed to TF, even more matted areas are produced (Fig. 6c). Thrombin addition after $\mathrm{CaCl}_{2}$ incubation has a similar effect (Fig. 6d). Recalcification of PPP with $\mathrm{CaCl}_{2}$, and subsequent exposure to TF and thrombin, results in no typical fibers being formed, as the matted areas extend over the whole area (Fig. 6e). By adding only thrombin to PPP, with no prior addition of calcium or TF, a typical fibrin network is formed (Fig. 6f).

\section{Fig. 6}

Fibrin networks of healthy controls with addition of certain coagulation factors. a Control PPP smear with no added factors. b Plasma incubated with $0.2 \mathrm{M}$ $\mathrm{CaCl}_{2}$ for 5 min. c Plasma incubated for $5 \mathrm{~min}$ with $0.2 \mathrm{M} \mathrm{CaCl}_{2}$, and subsequent addition of $2000 \mathrm{pM}$ TF. d Plasma incubated for 5 min with $0.2 \mathrm{M}$ $\mathrm{CaCl}_{2}$, and subsequent exposure to $2000 \mathrm{pM} \mathrm{TF}$ and thrombin. e Plasma incubated with $\mathrm{CaCl}_{2}$ for $5 \mathrm{~min}$, and subsequent exposure to thrombin. f Plasma exposed to thrombin. Scale bar indicates $1 \mu \mathrm{m}$. White arrow indicates thick matted deposits. 

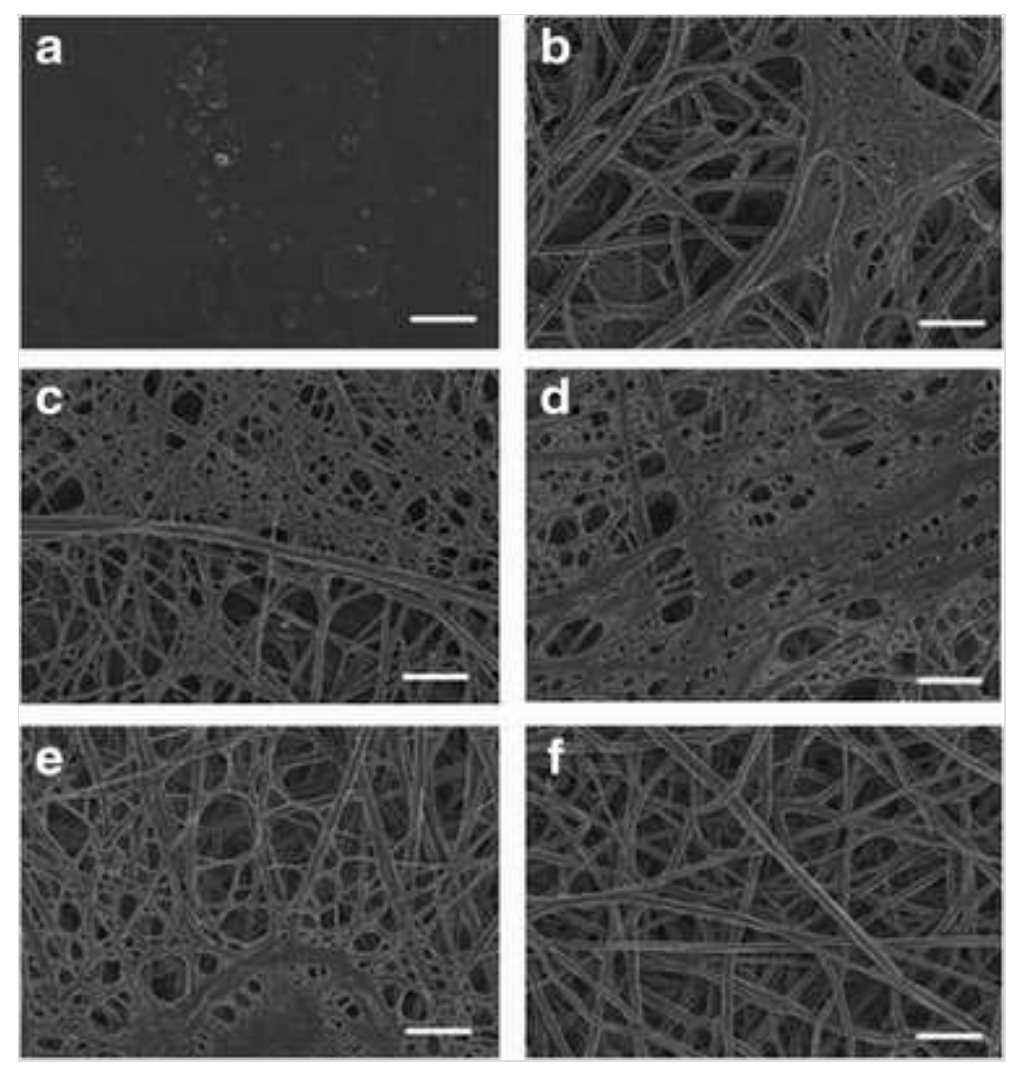

$\mathrm{CaCl}_{2}$ does not only influence the distribution of the fibers. $\mathrm{CaCl}_{2}$, in the presence of TF, causes the fibers to appear more coiled and bent (shown with white arrow in Fig. 7a). In the presence of $\mathrm{CaCl}_{2}$ and thrombin, the fibers have a spiral appearance (indicated with black arrow in Fig. 7b) with thin fibers extending from the thicker fibers.

\section{Fig. 7}

Plasma exposed to $\mathrm{CaCl}_{2}$ with other coagulation factors. a Plasma incubated for 5 min with $0.2 \mathrm{M} \mathrm{CaCl}_{2}$, with subsequent exposure to $2000 \mathrm{pM} \mathrm{TF}$. b Plasma incubated for 5 min with $0.2 \mathrm{M} \mathrm{CaCl}_{2}$, with subsequent exposure to Thrombin. Scale bar indicates $1 \mu \mathrm{m}$.
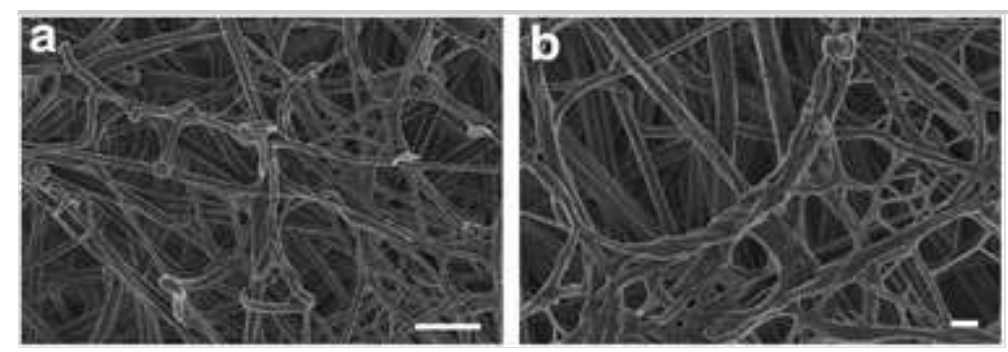

If citrate anticoagulation renders plasma essentially FXIII deficient secondary to hypocalcemia, then adding thrombin to such plasma will only show the results of thrombin-fibrinogen-fibrin interactions. If the thrombin activity is constant, then all changes in morphology must be fibrinogen (or modified 
fibrinogen) based.

From the morphological analysis, we can deduce that thrombin activation is the best way of investigating fibrin network morphology from citrated blood.

\section{Viscoelastic Analysis}

In an effort to further substantiate the claim that utilisation of citrated plasma exposed to thrombin is the optimal approach to assessing modifications of fibrinogen, a few illustrative experiments with viscoelastic methods were performed. In terms of experimental design, it is assumed that activated FXIII activity is calcium dependent $[16,177,178]$, and it is also known that FXIIImediated cross-linking is responsible for nearly $70 \%$ of the velocity of thrombus growth and strength [179, 180]. Normal pooled and FXIII-deficient plasma that was citrate anti-coagulated (George King Bio-Medical, Overland Park, KS, USA) was exposed to various concentrations of thrombin (Enzyme Research Laboratories, South Bend, IN, USA) inside disposable plastic cups placed in a computer-controlled thrombelastographic system (Model 5000, Haemoscope Corp., Niles, IL, USA) as previously described [179, 180]. In brief, $330 \mu \mathrm{l}$ of plasma was exposed to $30 \mu \mathrm{l}$ of distilled water with the indicated final concentration of thrombin, with velocity of thrombus formation (maximum rate of thrombus generations, MRTG, dynes $\mathrm{cm}^{-2} \mathrm{~s}^{-1}$ ) and clot strength (total thrombus generation, TTG, dynes $/ \mathrm{cm}^{2}$ ) determined. To compare the kinetic effects of essentially no FXIII activity to normal FXIII activity, additional citrated plasma was exposed to tissue factor $(10 \mu 1,0.1 \%$ final concentration in distilled water (Diagnostica Stago S.A.S., Asnieres sur Seine, France) and calcium chloride ( $20 \mu \mathrm{l}$ of $200 \mathrm{mM}$ solution). All conditions were replicated three times, and data are represented as mean plus standard deviation.

As can be seen in Fig. 8, MRTG increased in citrated plasma in a concentration-dependent manner, with little difference seen between 5 and $10 \mathrm{U} / \mathrm{ml}$ of thrombin noted. Similarly, in Fig. 9, TTG values increased in the same manner with increasing thrombin activity. Importantly, tissue factor/calcium-exposed plasma demonstrated both MRTG and TTG values triple that of citrated plasma exposed only to thrombin. This confirms kinetically that addition of thrombin to citrate anti-coagulated plasma results in clot formation that is essentially free of FXIII activity.

\section{Fig. 8}

Maximum rate of thrombus generations (MRTG) indicated as dynes per square 


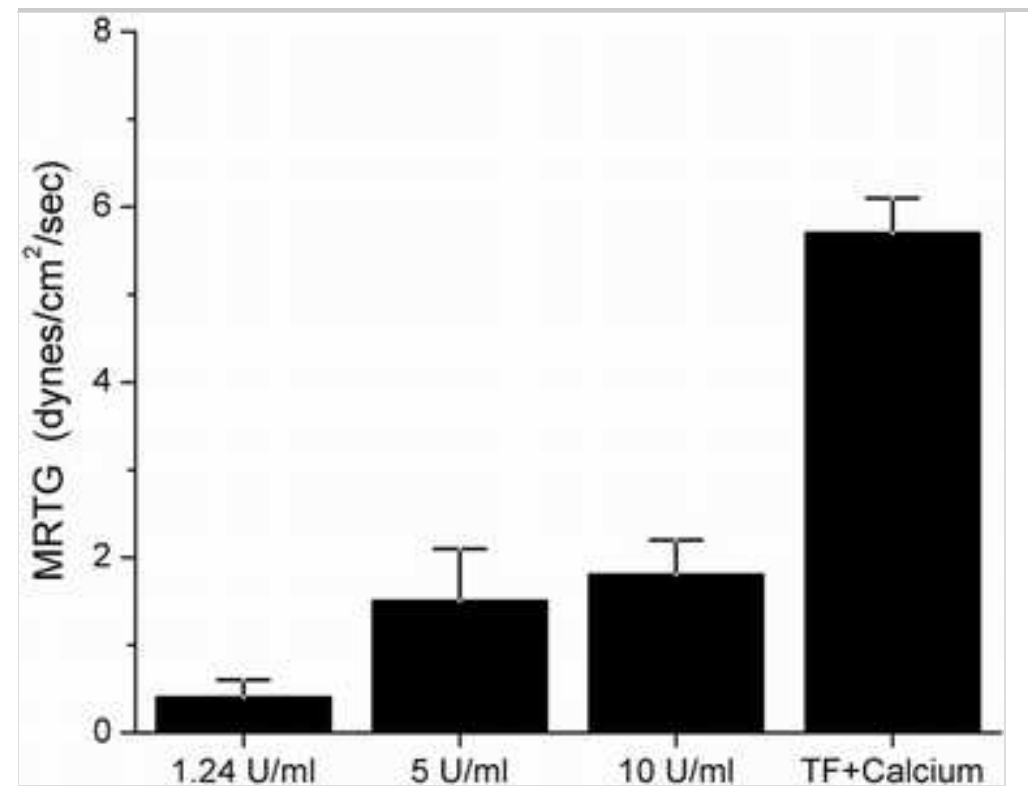

Fig. 9

Total thrombus generation $(T T G)$ indicated as dynes $/ \mathrm{cm}^{2}$.

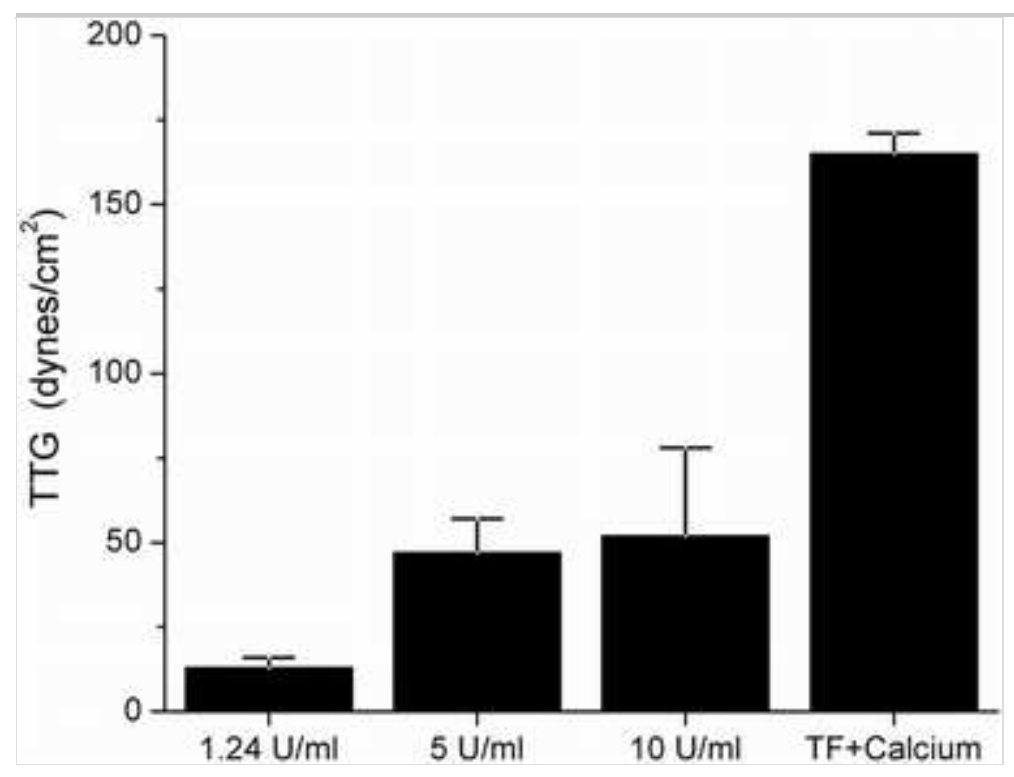

To further present this concept visually, we present thrombus growth velocity curves of thrombin-exposed, citrated plasma, tissue factor/calcium-exposed plasma and tissue factor/calcium-exposed FXIII-deficient plasma in Fig. 10. The peak velocities of growth (MRTG) are very similar between thrombinexposed citrated plasma and FXIII-deficient plasma exposed to tissue factor/calcium. The areas under these two curves (TTG) are very similar as well. Finally, both MRTG and TTG are three times greater in citrated plasma exposed to tissue factor/calcium than the other two conditions. Taken as a whole, the most direct way to assess the contribution of fibrinogen 
modifications to coagulation kinetics is to utilise citrated plasma with thrombin addition. The viscoelastic analysis therefore confirms the findings of the morphological analysis.

\section{Fig. 10}

Thrombus growth velocity curves indicated as dynes per square centimeter per second over time in seconds.

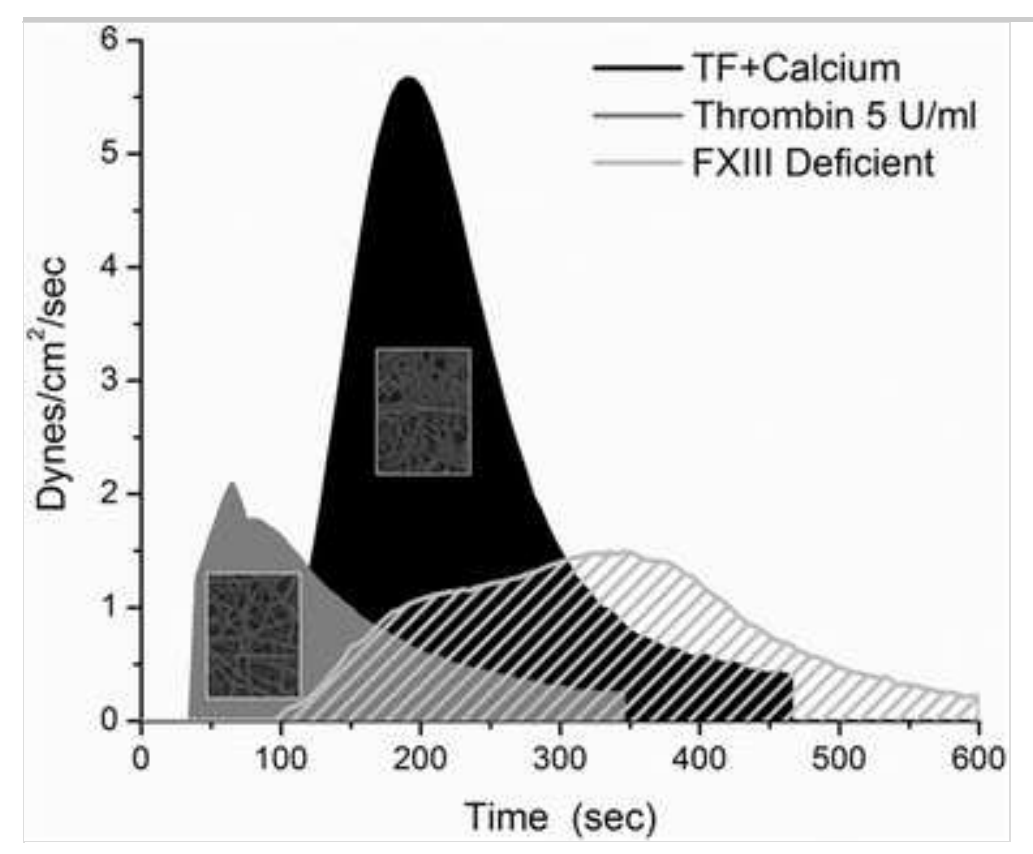

\section{MORPHOLOGY AND INFLAMMATORY DISEASE}

Pretorius and collaborators have investigated the effect of disease on the morphology of fibrin networks and platelets. These diseases include diabetes, thrombo-embolic ischaemic stroke, rheumatoid arthritis, hereditary hemochromatosis, cigarette smoking, systemic lupus erythematosus and asthma. Each of these exhibited alterations to morphology of platelets and fibrin networks. In addition, it is well known that inflammation is associated with each of these diseased states. See Table 3 for references to the morphological studies of each disease mentioned and studies referring to their association with inflammation.

\section{Table 3}

References to Inflammatory Correlation to Diseased States Associated with Altered Platelet and Fibrin Network Morphology

\begin{tabular}{|l|l|l|}
\hline \multicolumn{1}{|c|}{ Inflammatory disease } & Morphology & Inflammation \\
\hline Diabetes & {$[181]$} & {$[182]$} \\
\hline
\end{tabular}




\begin{tabular}{|l|l|l|}
\multicolumn{1}{|c|}{ Inflammatory disease } & \multicolumn{1}{|c|}{ Morphology } & \multicolumn{1}{|c|}{ Inflammation } \\
\hline Thrombo-embolic ischaemic stroke & {$[183]$} & {$[184]$} \\
\hline Rheumatoid arthritis & {$[185,186]$} & {$[187]$} \\
\hline Hereditary hemochromatosis & {$[188]$} & {$[189]$} \\
\hline Cigarette smoking & {$[190,191]$} & {$[192-194]$} \\
\hline Systemic lupus erythematosus & {$[195]$} & {$[196]$} \\
\hline Asthma & {$[197]$} & {$[198]$} \\
\hline
\end{tabular}

Diseases shown in Figs. 11 and 12 are all associated with inflammation.

These inflammatory states all show severe altered platelet and fibrin network morphology when prepared in the same manner as described in "Materials and methods".

\section{Fig. 11}

Morphology of platelets from diseases associated with inflammation and coagulation. a Diabetes. b Stroke. c Rheumatoid arthritis. d Lupus. Scale bar indicates $1 \mu \mathrm{m}$. White arrows indicate platelets, and black arrows indicate thick matted fibrin deposits.
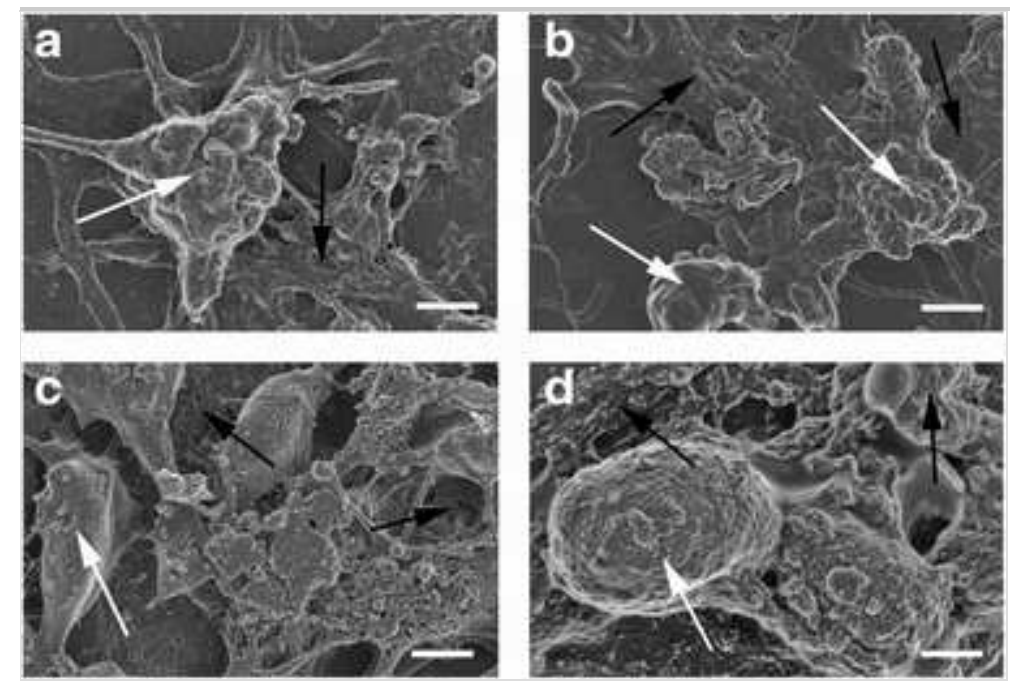

\section{Fig. 12}

Morphology of fibrin networks from diseases associated with inflammation and coagulation. a Diabetes. b Stroke. c Rheumatoid arthritis. d Lupus. Scale bar indicates $1 \mu \mathrm{m}$. 

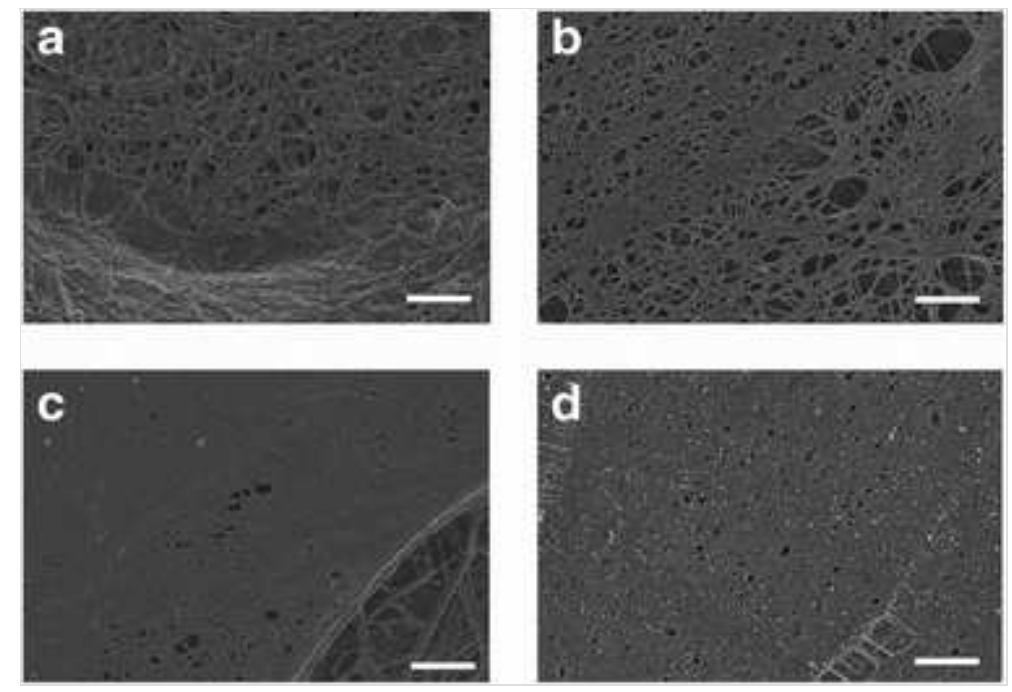

AQ4

Platelets show membrane blebbing, pseudopodia formation and spreading similar to activated platelets shown in Fig. 5 (platelets are indicated with white arrows in Fig. 11a-d). Thick matted deposits are also visible in the plasma smear, although no coagulation factors were added to the plasma (indicated with black arrows in Fig. 12a-d). Activation of plasma with thrombin showed additional activation of the fibrin network since extensive thick matted deposits with very few typical fibers are exhibited (Fig. 12a-d), which correlate with the morphological changes seen in Fig. 6.

Over-activation of the coagulation system through $\mathrm{TF}, \mathrm{CaCl}_{2}$ and thrombin thus show similarities to the morphological changes in platelet and fibrin network ultrastructure seen in inflammatory disease.

\section{CONCLUSION}

A great amount of research has been done on the coagulation system and the properties of its associated pathophysiology, specifically on the biochemical front. The close interrelated biochemistry of coagulation and inflammation, especially concerning alterations in the coagulation factors, is well documented, although morphological methodologies have not been given much attention.

Tissue factor, calcium and thrombin, which all play an integral role in the coagulation cascade, have been implicated in the inflammatory response. The addition of concentrations of TF and calcium shown via coagulation kinetics to provide maximal values may "over-activate" samples, making differentiation of platelet or fibrin specific changes difficult to detect. When 
platelet morphology is investigated, washed platelets need to be prepared without addition of any other products of coagulation factors to ensure accurate results when disease is investigated. Induced platelet activation through the addition of $\mathrm{TF}, \mathrm{CaCl}_{2}$ or thrombin will mask disease-induced platelet alterations associated with activation. Thrombin is one of the fundamental coagulation factors not only responsible for fibrin formation but also for feedback to the rest of the cascade. The exclusive addition of thrombin optimises the ability to assess fibrin network formation with ultrastructural analysis.

The morphological changes associated with over-activation of the coagulation system after addition of the mentioned coagulation factors is similar to the alterations observed in inflammatory diseases. Platelet activation and thick matted fibrin deposits seen in diseases like rheumatoid arthritis strongly indicate that inflammation induces coagulation. Ultrastructural analysis of platelets and fibrin networks are essential in understanding the aetiology of inflammatory disease. Blood is transported throughout the body. The over-activated state observed in the mentioned inflammatory diseases is thus present throughout the whole body. These morphological alterations discussed can be viewed as the "beginning of the end". The use of ultrastructural methodologies like scanning electron microscopy should, therefore, form a vital part in investigation of disease. By studying the morphology of platelets and fibrin networks, specific drug targets and treatment plans along with focus for further research can be justified.

The intricate connection between coagulation and inflammation makes morphological analysis an essential tool for future research.

Conflict of Interest The authors declare that they have no conflict of interest.

Authorship All three authors made substantial contributions to manuscript in accordance with the ICMJE 2013 authorship criteria.

\section{References}

1. Gasparyan, A.Y., L. Ayvazyan, H. Blackmore, and G.D. Kitas. 2011. Writing a narrative biomedical review: Considerations for authors, peer reviewers, and editors. Rheumatology International 31(11): 1409-1417. 
2. Owen, C.A. (2001) A history of blood coagulation. In, ed. Nichols, W.L., Bowie, E.J.W., Rochester: Mayo Foundation for Medical Education and Research.

AQ5

3. Connor, W.E. 1958. The chemistry of blood coagulation. A.M.A. Archives of Internal Medicine 102(4): 681-682.

4. Brewer, D.B. 2006. Max Schultze (1865), G. Bizzozero (1882) and the discovery of the platelet. British Journal of Haematology 133(3): 251-258.

5. Ribatti, D., and E. Crivellato. 2007. Giulio Bizzozero and the discovery of platelets. Leukemia Research 31(10): 1339-1341.

6. Dahlbäck, B. 2000. Blood coagulation. Lancet 355(9215): 1627-1632.

7. Norris, L.A. 2003. Blood coagulation. Best Practice and Research: Clinical Obstetrics and Gynaecology 17(3): 369-383.

8. Davie, E.W. 1995. Biochemical and molecular aspects of the coagulation cascade. Thrombosis and Haemostasis 74(1): 1-6.

9. Macfarlane, R.G. 1964. An enzyme cascade in the blood clotting mechanism, and its function as a biochemical amplifier. Nature 202(4931): 498-499.

10. Monroe, D.M., H.R. Roberts, and M. Hoffman. 1994. Platelet procoagulant complex assembly in a tissue factor-initiated system. British Journal of Haematology 88(2): 364-371.

11. Hoffman, M., D.M. Monroe, J.A. Oliver, and H.R. Roberts. 1995. Factors IXa and Xa play distinct roles in tissue factor-dependent initiation of coagulation. Blood 86(5): 1794-1801.

12. Monroe, D.M., M. Hoffman, and H.R. Roberts. 1996. Transmission of a procoagulant signal from tissue factor-bearing cells to platelets. Blood Coagulation and Fibrinolysis 7(4): 459-464.

13. Pérez-Gómez, F., and R. Bover. 2007. The new coagulation cascade and its possible influence on the delicate balance between thrombosis and 
hemorrhage. La nueva cascada de la coagulación y su posible influencia en el difícil equilibrio entre trombosis y hemorragia. Revista Espanola de Cardiologia

AQ8

$A Q^{9}$

60(12): 1217-1219.

14. Hoffman, M., and D.M. Monroe. 2007. Coagulation 2006: a modern view of hemostasis. Hematology/Oncology Clinics of North America 21(1): $1-11$.

15. Smith, S.A. 2009. The cell-based model of coagulation: Stateof-the-art review. Journal of Veterinary Emergency and Critical Care 19(1): 3-10.

16. Hornyak, T.J., and J.A. Shafer. 1991. Role of calcium ion in the generation of factor XIII activity. Biochemistry 30(25): 6175-6182.

17. Adany, R., and H. Bardos. 2003. Factor XIII subunit A as an intracellular transglutaminase. Cellular and Molecular Life Sciences CMLS 60(6): 1049-1060.

18. Janus, T.J., S.D. Lewis, L. Lorand, and J.A. Shafer. 1983. Promotion of thrombin-catalyzed activation of factor XIII by fibrinogen. Biochemistry 22(26): 6269-6272.

19. Hoffman, M. 2003. Remodeling the blood coagulation cascade. Journal of Thrombosis and Thrombolysis 16(1-2): 17-20.

20. Hoffman, M., and D.M. Monroe Iii. 2001. A cell-based model of hemostasis. Thrombosis and Haemostasis 85(6): 958-965.

21. Campbell, R.A., K.A. Overmyer, C.H. Selzman, B.C. Sheridan, and A.S. Wolberg. 2009. Contributions of extravascular and intravascular cells to fibrin network formation, structure, and stability. Blood 114(23): 4886-4896.

22. Mann, K.G. 1993. Introduction: Blood coagulation. Methods in Enzymology 222: 1-10. 
23. Furie, B., and B.C. Furie. 1992. Molecular and cellular biology of blood coagulation. New England Journal of Medicine 326(12): 800-806.

24. Kirchhofer, D., and Y. Nemerson. 1996. Initiation of blood coagulation: the tissue factor/factor VIIa complex. Current Opinion in Biotechnology 7(4): 386-391.

25. Mann, K.G., C. Van't Veer, K. Cawthern, and S. Butenas. 1998. The role of the tissue factor pathway in initiation of coagulation. Blood Coagulation and Fibrinolysis 9(SUPPL. 1): S3-S7.

26. Hoffman, M., D.M. Monroe, and H.R. Roberts. 1996. Cellular interactions in hemostasis. Haemostasis 26(SUPPL. 1): 12-16.

27. Zwaal, R.F.A., P. Comfurius, and E.M. Bevers. 1998. Lipid-protein interactions in blood coagulation. Biochimica et Biophysica Acta-Reviews on Biomembranes 1376(3): 433-453.

28. Sadler, J.E. 1998. Biochemistry and genetics of von Willebrand factor. Annual Review of Biochemistry 67: 395-424.

29. Gailani, D., and G.J. Broze Jr. 1991. Factor XI activation in a revised model of blood coagulation. Science 253(5022): 909-912.

30. Lammle, B., W.A. Wuillemin, I. Huber, M. Krauskopf, C. Zurcher, R. Pflugshaupt, and M. Furlan. 1991. Thromboembolism and bleeding tendency in congenital factor XII deficiency-A study on 74 subjects from 14 Swiss families. Thrombosis and Haemostasis 65(2): 117-121.

31. Bugge, T.H., Q. Xiao, K.W. Kombrinck, M.J. Flick, K. Holmback, M.J.S. Danton, M.C. Colbert, D.P. Witte, K. Fujikawa, E.W. Davie, et al. 1996. Fatal embryonic bleeding events in mice lacking tissue factor, the cell- associated initiator of blood coagulation. Proceedings of the National Academy of Sciences of the United States of America 93(13): 6258-6263.

32. Camerer, E., A.B.. Kolstø, and H. Prydz. 1996. Cell biology of tissue factor, the principal initiator of blood coagulation. Thrombosis Research 81(1): 1-41.

33. Morrissey, J.H. 2001. Tissue factor: An enzyme cofactor and a true 
34. Heinrich, J., L. Balleisen, H. Schulte, G. Assmann, and J. Van de Loo. 1994. Erratum: Fibrinogen and factor VII in the prediction of coronary risk: Results from the PROCAM study in healthy men (Arteriosclerosis and Thrombosis (1994) 14 (54-59)). Arteriosclerosis and Thrombosis 14(8): 1392.

35. Meade, T.W., S. Mellows, M. Brozovic, G.J. Miller, R.R. Chakrabarti, W.R. North, A.P. Haines, Y. Stirling, J.D. Imeson, and S.G. Thompson. 1986. Haemostatic function and ischaemic heart disease: Principal results of the Northwick Park Heart Study. Lancet 2(8506): 533-537.

36. Scott, C.F., L.D. Silver, A.D. Purdon, and R.W. Colman. 1985. Cleavage of human high molecular weight kininogen by factor XIa in vitro: Effect on structure and function. Journal of Biological Chemistry 260(19): 10856-10863.

37. Asakai, R., D.W. Chung, E.W. Davie, and U. Seligsohn. 1991. Factor $\mathrm{XI}$ deficiency in Ashkenazi Jews in Israel. New England Journal of Medicine 325(3): 153-158.

38. Meijers, J.C.M., W.L.H. Tekelenburg, B.N. Bouma, R.M. Bertina, and F.R. Rosendaal. 2000. High levels of coagulation factor XI as a risk factor for venous thrombosis. New England Journal of Medicine 342(10): 696-701.

39. Colman, R.W. 1999. Biologic activities of the contact factors in vivo. Potentiation of hypotension, inflammation, and fibrinolysis, and inhibition of cell adhesion, angiogenesis and thrombosis. Thrombosis and Haemostasis 82(6): 1568-1577.

40. Nesheim, M., D.D. Pittman, A.R. Giles, D.N. Fass, J.H. Wang, D. Slonosky, and R.J. Kaufman. 1991. The effect of plasma von Willebrand factor on the binding of human factor VIII to thrombin-activated human platelets. Journal of Biological Chemistry 266(27): 17815-17820.

41. Hamer, R.J., J.A. Koedam, N.H. Beeser-Visser, and J.J. Sixma. 1987. The effect of thrombin on the complex between factor VIII and von Willebrand factor. European Journal of Biochemistry 167(2): 253-259. 
42. Bertina, R.M., B.P.C. Koeleman, T. Koster, F.R. Rosendaal, R.J. Dirven, H. De Ronde, P.A. Van Der Velden, and P.H. Reitsma. 1994. Mutation in blood coagulation factor $\mathrm{V}$ associated with resistance to activated protein C. Nature 369(6475): 64-67.

43. Nesheim, M.E., J.B. Taswell, and K.G. Mann. 1979. The contribution of bovine factor $\mathrm{V}$ and factor Va to the activity of prothrombinase. Journal of Biological Chemistry 254(21): 10952-10962.

44. Doyle, M.F., and P.E. Haley. 1993. Meizothrombin: active intermediate formed during prothrombinase-catalyzed activation of Prothrombin. Methods in Enzymology 222: 299-312.

45. Bauer, K.A. 1999. Activation markers of coagulation. Bailliere's Best Practice and Research in Clinical Haematology 12(3): 387-406.

46. Poort, S.R., F.R. Rosendaal, P.H. Reitsma, and R.M. Bertina. 1996. A common genetic variation in the $3^{\prime}$-untranslated region of the prothrombin gene is associated with elevated plasma prothrombin levels and an increase in venous thrombosis. Blood 88(10): 3698-3703.

47. Brummel, K.E., S.G. Paradis, S. Butenas, and K.G. Mann. 2002. Thrombin functions during tissue factor-induced blood coagulation. Blood 100(1): 148-152.

48. Tulinsky, A. 1996. Molecular interactions of thrombin. Seminars in Thrombosis and Hemostasis 22(2): 117-124.

49. Weisel, J.W. 1986. Fibrin assembly. Lateral aggregation and the role of the two pairs of fibrinopeptides. Biophysical Journal 50(6): 1079-1093.

50. Wojtukiewicz, M.Z., E. Sierko, P. Klement, and J. Rak. 2001. The hemostatic system and angiogenesis in malignancy. Neoplasia 3(5): 371-384.

51. Davie, E.W., K. Fujikawa, and W. Kisiel. 1991. The coagulation cascade: Initiation, maintenance, and regulation. Biochemistry 30(43): 10363-10370.

52. Esmon, C.T. 2000. Regulation of blood coagulation. Biochimica et 
Biophysica Acta - Protein Structure and Molecular Enzymology 1477(1-2): 349-360.

53. Mann, K.G., K. Brummel-Ziedins, T. Orfeo, and S. Butenas. 2006. Models of blood coagulation. Blood Cells, Molecules, and Diseases 36(2): 108-117.

54. Mann, K.G. 1999. Biochemistry and physiology of blood coagulation. Thrombosis and Haemostasis 82(2): 165-174.

55. Jackson, C.M., and Y. Nemerson. 1980. Blood coagulation. Annual Review of Biochemistry 49(1): 765-811.

56. Zarbock, A., R.K. Polanowska-Grabowska, and K. Ley. 2007. Plateletneutrophil-interactions: linking hemostasis and inflammation. Blood Reviews 21(2): 99-111.

57. Kenny, L., P. Baker, and F.G. Cunningham. 2009. Platelets, coagulation, and the liver. Chesley's hypertension in pregnancy, $3 \mathrm{rd}$ edn, 335. New York: Elsevier.

58. Mosnier, L.O., P. Buijtenhuijs, P.F. Marx, J.C. Meijers, and B.N. Bouma. 2003. Identification of thrombin activatable fibrinolysis inhibitor (TAFI) in human platelets. Blood 101(12): 4844-4846.

59. Frenette, P.S., R.C. Johnson, R.O. Hynes, and D.D. Wagner. 1995. Platelets roll on stimulated endothelium in vivo: an interaction mediated by endothelial P-selectin. Proceedings of the National Academy of Sciences 92(16): 7450-7454.

60. Frenette, P.S., C. Moyna, D.W. Hartwell, J.B. Lowe, R.O. Hynes, and D.D. Wagner. 1998. Platelet-endothelial interactions in inflamed mesenteric venules. Blood 91(4): 1318-1324.

61. Majerus, P. 1987. Platelets. In The molecular basis of blood diseases, ed. G. Stamatoyannopoulos, A.W. Nienhuis, P. Leder, and P. Majerus. Philadelphia: W.B. Saunders Co.

62. Girma, J.P., D. Meyer, C.L. Verweij, H. Pannekoek, and J.J. Sixma. 1987. Structure-function relationship of human von Willebrand factor. 
63. Ruggeri, Z.M., and T.S. Zimmerman. 1987. Von Willebrand factor and von Willebrand disease. Blood 70(4): 895-904.

64. Lopez, J.A., D.W. Chung, K. Fujikawa, F.S. Hagen, E.W. Davie, and G.J. Roth. 1988. The $\alpha$ and $\beta$ chains of human platelet glycoprotein Ib are both transmembrane proteins containing a leucine-rich amino acid sequence. Proceedings of the National Academy of Sciences of the United States of America 85(7): 2135-2139.

65. Bennett, J.S., G. Vilaire, and D.B. Cines. 1982. Identification of the fibrinogen receptor on human platelets by photoaffinity labeling. Journal of Biological Chemistry 257(14): 8049-8054.

66. Savage, B., and Z.M. Ruggeri. 1991. Selective recognition of adhesive sites in surface-bound fibrinogen by glycoprotein IIb-IIIa on nonactivated platelets. Journal of Biological Chemistry 266(17): 11227-11233.

67. Varga-Szabo, D., A. Braun, and B. Nieswandt. 2009. Calcium signaling in platelets. Journal of Thrombosis and Haemostasis 7(7): 1057-1066.

68. Bergmeier, W., and L. Stefanini. 2009. Novel molecules in calcium signaling in platelets. Journal of Thrombosis and Haemostasis 7(SUPPL. 1): $187-190$.

69. Rink, T., and S. Sage. 1990. Calcium signaling in human platelets. Annual Review of Physiology 52(1): 431-449.

70. Neeves, K., D. Illing, and S. Diamond. 2010. Thrombin flux and wall shear rate regulate fibrin fiber deposition state during polymerization under flow. Biophysical Journal 98(7): 1344-1352.

71. Ferri, F., M. Greco, G. Arcovito, M. De Spirito, and M. Rocco. 2002. Structure of fibrin gels studied by elastic light scattering techniques: dependence of fractal dimension, gel crossover length, fiber diameter, and fiber density on monomer concentration. Physical Review E 66(1): 011913.

72. Yeromonahos, C., B. Polack, and F. Caton. 2010. Nanostructure of the 
73. Yang, Z., J.M. Kollman, L. Pandi, and R.F. Doolittle. 2001. Crystal structure of native chicken fibrinogen at $2.7 \AA$ resolution. Biochemistry 40(42): 12515-12523.

74. Ferry, J.D., and P.R. Morrison. 1947. Preparation and properties of serum and plasma proteins. IX. Human fibrin in the form of an elastic film. Journal of the American Chemical Society 69(2): 400-409.

75. Fowler, W., R. Hantgan, J. Hermans, and H. Erickson. 1981. Structure of the fibrin protofibril. Proceedings of the National Academy of Sciences 78(8): 4872-4876.

76. Clark, R.A. (1996) The molecular and cellular biology of wound repair. Springer.

AQ10

77. Piechocka, I.K., R.G. Bacabac, M. Potters, F.C. Mackintosh, and G.H. Koenderink. 2010. Structural hierarchy governs fibrin gel mechanics. Biophysical Journal 98(10): 2281-2289.

78. Weisel, J.W. 2004. The mechanical properties of fibrin for basic scientists and clinicians. Biophysical Chemistry 112(2-3 SPEC. ISS): 267-276.

79. Liu, W., L.M. Jawerth, E.A. Sparks, M.R. Falvo, R.R. Hantgan, R. Superfine, S.T. Lord, and M. Guthold. 2006. Fibrin fibers have extraordinary extensibility and elasticity. Science 313(5787): 634.

80. Brown, A.E.X., R.I. Litvinov, D.E. Discher, P.K. Purohit, and J.W. Weisel. 2009. Multiscale mechanics of fibrin polymer: Gel stretching with protein unfolding and loss of water. Science 325(5941): 741-744.

81. Shah, J.V., and P.A. Janmey. 1997. Strain hardening of fibrin gels and plasma clots. Rheologica Acta 36(3): 262-268.

82. Wen, Q., A. Basu, J.P. Winer, A. Yodh, and P.A. Janmey. 2007. Local and global deformations in a strain-stiffening fibrin gel. New Journal of Physics 9(11): 428. 
83. Kang, H., Q. Wen, P.A. Janmey, J.X. Tang, E. Conti, and F.C. MacKintosh. 2009. Nonlinear elasticity of stiff filament networks: Strain stiffening, negative normal stress, and filament alignment in fibrin gels. Journal of Physical Chemistry B 113(12): 3799-3805.

84. Roberts, W.W., L. Lorand, and L.F. Mockros. 1973. Viscoelastic properties of fibrin clots. Biorheology 10(1): 29-42.

85. Yao, N.Y., R.J. Larsen, and D.A. Weitz. 2008. Probing nonlinear rheology with inertio-elastic oscillations. Journal of Rheology 52(4): 1013-1025.

86. Janmey, P.A., E.J. Amis, and J.D. Ferry. 1983. Rheology of fibrin clots-6. Stress relaxation, creep, and differential dynamic modulus of fine clots in large shearing deformations. Journal of Rheology 27(2): 135-153.

87. Bale, M.D., and J.D. Ferry. 1988. Strain enhancement of elastic modulus in fine fibrin clots. Thrombosis Research 52(6): 565-572.

88. Gardel, M.L., J.H. Shin, F.C. MacKintosh, L. Mahadevan, P. Matsudaira, and D.A. Weitz. 2004. Elastic behavior of cross-linked and bundled actin networks. Science 304(5675): 1301-1305.

89. Ryan, E.A., L.F. Mockros, J.W. Weisel, and L. Lorand. 1999. Structural origins of fibrin clot rheology. Biophysical Journal 77(5): 2813-2826.

90. Xu, J., Y. Tseng, and D. Wirtz. 2000. Strain hardening of actin filament networks: regulation by the dynamic cross-linking protein $\alpha$-actinin. Journal of Biological Chemistry 275(46): 35886-35892.

91. Janmey, P.A., M.E. McCormick, S. Rammensee, J.L. Leight, P.C. Georges, and F.C. MacKintosh. 2007. Negative normal stress in semiflexible biopolymer gels. Nature Materials 6(1): 48-51.

92. Hudson, N.E., J.R. Houser, E.T. O’Brien Iii, R.M. Taylor Ii, R. Superfine, S.T. Lord, and M.R. Falvo. 2010. Stiffening of individual fibrin fibers equitably distributes strain and strengthens networks. Biophysical Journal 98(8): 1632-1640. 
93. Falvo, M.R., D. Millard, E.T. O'Brien Iii, R. Superfine, and S.T. Lord. 2008. Length of tandem repeats in fibrin's $\alpha \mathrm{C}$ region correlates with fiber extensibility. Journal of Thrombosis and Haemostasis 6(11): 1991-1993.

94. Guthold, M., W. Liu, E.A. Sparks, L.M. Jawerth, L. Peng, M. Falvo, R. Superfine, R.R. Hantgan, and S.T. Lord. 2007. A comparison of the mechanical and structural properties of fibrin fibers with other protein fibers. Cell Biochemistry and Biophysics 49(3): 165-181.

95. Liu, W., C.R. Carlisle, E.A. Sparks, and M. Guthold. 2010. The mechanical properties of single fibrin fibers. Journal of Thrombosis and Haemostasis 8(5): 1030-1036.

96. Storm, C., J.J. Pastore, F.C. MacKintosh, T.C. Lubensky, and P.A. Janmey. 2005. Nonlinear elasticity in biological gels. Nature 435(7039): 191-194.

97. Wolberg, A.S. 2007. Thrombin generation and fibrin clot structure. Blood Reviews 21(3): 131-142.

98. Wolberg, A.S., and R.A. Campbell. 2008. Thrombin generation, fibrin clot formation and hemostasis. Transfusion and Apheresis Science 38(1): $15-23$.

99. Müller, I., A. Klocke, M. Alex, M. Kotzsch, T. Luther, E.

Morgenstern, S. Zieseniss, S. Zahler, K. Preissner, and B. Engelmann. 2003. Intravascular tissue factor initiates coagulation via circulating microvesicles and platelets. The FASEB Journal 17(3): 476-478.

100. Banner, D.W., A. D'Arcy, C. Chene, F.K. Winkler, A. Guha, W.H. Konigsberg, Y. Nemerson, and D. Kirchhofer. 1996. The crystal structure of the complex of blood coagulation factor VIIa with soluble tissue factor. Nature 380(6569): 41-46.

101. Hantgan, R.R., G. Hindriks, R.G. Taylor, J.J. Sixma, and P.G. de Groot. 1990. Glycoprotein Ib, von Willebrand factor, and glycoprotein IIb: IIIa are all involved in platelet adhesion to fibrin in flowing whole blood. Blood 76(2): 345-353.

102. Lages, B., and H.J. Weiss. 1994. Evidence for a role of glycoprotein 
IIb-IIIa, distinct from its ability to support aggregation, in platelet activation by ionophores in the presence of extracellular divalent cations. Blood 83(9): 2549-2559.

103. Cierniewski, C.S., J.W. Smith, E.F. Plow, and T. Haas. 1994. Characterization of cation-binding sequences in the platelet integrin GPIIb-IIIa (. alpha. IIb. beta. 3) by terbium luminescence. Biochemistry 33(40): 12238-12246.

104. Rivas, G., and J. Gonzalez-Rodriguez. 1991. Calcium binding to human platelet integrin GPIIb/IIIa and to its constituent glycoproteins. Effects of lipids and temperature. The Biochemical Journal 276: 35-40.

105. Münzer, P., A. Tolios, L. Pelzl, E. Schmid, E.M. Schmidt, B. Walker, H. Fröhlich, O. Borst, M. Gawaz, and F. Lang. 2013. Thrombin-sensitive expression of the store operated $\mathrm{Ca}^{2+}$ channel Orail in platelets.

Biochemical and Biophysical Research Communications 436(1): 25-30.

106. Curtis, C., K. Brown, R. Credo, R. Domanik, A. Gray, P. Stenberg, and L. Lorand. 1974. Calcium-dependent unmasking of active center cysteine during activation of fibrin stabilizing factor. Biochemistry 13(18): 3774-3780.

107. Lorand, L., A.J. Gray, K. Brown, R.B. Credo, C.G. Curtis, R.A. Domanik, and P. Stenberg. 1974. Dissociation of the subunit structure of fibrin stabilizing factor during activation of the zymogen. Biochemical and Biophysical Research Communications 56(4): 914-922.

108. Kitchens, C.S., and T.F. Newcomb. 1979. Factor XIII. Medicine 58(6): 413-429.

109. Nemerson, Y., and D. Repke. 1985. Tissue factor accelerates the activation of coagulation factor VII: The role of a bifunctional coagulation cofactor. Thrombosis Research 40(3): 351-358.

110. Rao, L., and S.I. Rapaport. 1988. The effect of platelets upon factor Xa-catalyzed activation of factor VII in vitro. Blood 72(2): 396-401.

111. Sakai, T., T. Lund-Hansen, L. Paborsky, A. Pedersen, and W. Kisiel. 1989. Binding of human factors VII and VIIa to a human bladder 
carcinoma cell line (J82). Implications for the initiation of the extrinsic pathway of blood coagulation. Journal of Biological Chemistry 264(17): 9980-9988.

112. Eaton, D., H. Rodriguez, and G.A. Vehar. 1986. Proteolytic processing of human factor VIII. Correlation of specific cleavages by thrombin, factor $\mathrm{Xa}$, and activated protein $\mathrm{C}$ with activation and inactivation of factor VIII coagulant activity. Biochemistry 25(2): 505-512.

113. Di Scipio, R.G., K. Kurachi, and E.W. Davie. 1978. Activation of human factor IX (Christmas factor). Journal of Clinical Investigation 61(6): 1528.

114. Lorand, L., and K. Konishi. 1964. Activation of the fibrin stabilizing factor of plasma by thrombin. Archives of Biochemistry and Biophysics 105(1): 58-67.

115. Naski, M.C., L. Lorand, and J.A. Shafer. 1991. Characterization of the kinetic pathway for fibrin promotion of. alpha-thrombin-catalyzed activation of plasma factor XIII. Biochemistry 30(4): 934-941.

116. Kisiel, W., W.M. Canfield, L.H. Ericsson, and E.W. Davie. 1977. Anticoagulant properties of bovine plasma protein $\mathrm{C}$ following activation by thrombin. Biochemistry 16(26): 5824-5831.

117. Marlar, R.A., A.J. Kleiss, and J.H. Griffin. 1982. Mechanism of action of human activated protein $\mathrm{C}$, a thrombin-dependent anticoagulant enzyme. Blood 59(5): 1067-1072.

118. Vehar, G.A., and E.W. Davie. 1980. Preparation and properties of bovine factor VIII (antihemophilic factor). Biochemistry 19(3): 401-410.

119. Walker, F.J. 1980. Regulation of activated protein $C$ by a new protein. A possible function for bovine protein S. Journal of Biological Chemistry 255(12): 5521-5524.

120. Huntington, J.A. 2008. How $\mathrm{Na}+$ activates thrombin-A review of the functional and structural data. Biological Chemistry 389(8): $1025-1035$. 
121. Lechtenberg, B.C., S.M.V. Freund, and J.A. Huntington. 2012. An ensemble view of thrombin allostery. Biological Chemistry 393(9): 889-898.

122. De Candia, E. 2012. Mechanisms of platelet activation by thrombin: a short history. Thrombosis Research 129(3): 250-256.

123. Weiss, U. 2008. Inflammation. Nature 454(7203): 427.

124. Medzhitov, R. 2008. Origin and physiological roles of inflammation. Nature 454(7203): 428-435.

125. Feghali, C.A., and T.M. Wright. 1997. Cytokines in acute and chronic inflammation. Frontiers in Bioscience : A Journal and Virtual Library 2: d12-d26.

126. Cicala, C., and G. Cirino. 1998. Linkage between inflammation and coagulation: an update on the molecular basis of the crosstalk. Life Sciences 62(20): 1817-1824.

127. Libby, P., and D.I. Simon. 2001. Inflammation and thrombosis: The clot thickens. Circulation 103(13): 1718-1720.

128. Gasparyan, A. 2010. Platelets in inflammation and thrombosis. Inflammation \& Allergy Drug Targets 9(5): 319.

129. Gasparyan, A.Y., L. Ayvazyan, D.P. Mikhailidis, and G.D. Kitas. 2011. Mean platelet volume: a link between thrombosis and inflammation? Current Pharmaceutical Design 17(1): 47-58.

130. Gasparyan, A., A. Sandoo, A. Stavropoulos-Kalinoglou, and G. Kitas. 2010. Mean platelet volume in patients with rheumatoid arthritis: the effect of anti-TNF-alpha therapy. Rheumatology International 30(8): $1125-1129$.

131. Gasparyan, A.Y., A. Stavropoulos-Kalinoglou, T.E. Toms, K.M. Douglas, and G.D. Kitas. 2010. Association of mean platelet volume with hypertension in rheumatoid arthritis. Inflammation \& Allergy-Drug Targets (Formerly Current Drug Targets-Inflammation \& Allergy) 9(1): 45-50. 
132. Gawaz, M. 2004. Role of platelets in coronary thrombosis and reperfusion of ischemic myocardium. Cardiovascular Research 61(3): 498-511.

133. Borst, O., P. Münzer, S. Gatidis, E.M. Schmidt, T. Schönberger, E. Schmid, S.T. Towhid, K. Stellos, P. Seizer, A.E. May, et al. 2012. The inflammatory chemokine CXC motif ligand 16 triggers platelet activation and adhesion via CXC motif receptor 6-dependent phosphatidylinositide 3-kinase/akt signaling. Circulation Research 111(10): 1297-1307.

134. Gasparyan, A., A. Stavropoulos-Kalinoglou, D. Mikhailidis, K.J. Douglas, and G. Kitas. 2011. Platelet function in rheumatoid arthritis: arthritic and cardiovascular implications. Rheumatology International 31(2): 153-164.

135. Burstein, S. 1997. Cytokines, platelet production and hemostasis. Platelets 8(2-3): 93-104.

136. Pendurthi, U.R., D. Alok, and L.V.M. Rao. 1997. Binding of factor VIIa to tissue factor induces alterations in gene expression in human fibroblast cells: up-regulation of poly(A) polymerase. Proceedings of the National Academy of Sciences of the United States of America 94(23): 12598-12603.

137. Miller, D.L., R. Yaron, and M.J. Yellin. 1998. CD40L-CD40 interactions regulate endothelial cell surface tissue factor and thrombomodulin expression. Journal of Leukocyte Biology 63(3): 373-379.

138. André, P., K.S. Srinivasa Prasad, C.V. Denis, M. He, J.M. Papalia, R.O. Hynes, D.R. Phillips, and D.D. Wagner. 2002. CD40L stabilizes arterial thrombi by a $\beta 3$ integrin-dependent mechanism. Nature Medicine 8(3): $247-252$.

139. Henn, V., J.R. Slupsky, M. Gräfe, I. Anagnostopoulos, R. Förster, G. Müller-Berghaus, and R.A. Kroczek. 1998. CD40 ligand on activated platelets triggers an inflammatory reaction of endothelial cells. Nature 391(6667): 591-594.

140. Loppnow, H., R. Bil, S. Hirt, U. Schönbeck, M. Herzberg, K. Werdan, E.T. Rietschel, E. Brandt, and H.D. Flad. 1998. Platelet-derived 
interleukin-1 induces cytokine production, but not proliferation of human vascular smooth muscle cells. Blood 91(1): 134-141.

141. Opal, S.M., and C.T. Esmon. 2003. Bench-to-bedside review: Functional relationships between coagulation and the innate immune response and their respective roles in the pathogenesis of sepsis. Critical Care 7(1): 23-38.

142. Kuijper, P.H.M., H.I. Gallardo Torres, J.A.M. Van Der Linden, J.W.J. Lammers, J.J. Sixma, L. Koenderman, and J.J. Zwaginga. 1996. Plateletdependent primary hemostasis promotes selectin- and integrin-mediated neutrophil adhesion to damaged endothelium under flow conditions. Blood 87(8): 3271-3281.

143. Corken, A., Russell, S., Dent, J., Post, S.R., Ware, J. (2014) Platelet glycoprotein Ib-IX as a regulator of systemic inflammation. Arteriosclerosis, Thrombosis, and Vascular Biology. doi: 10.1161/ATVBAHA.113.303113.

AQ11

144. Petäjä, J. 2011. Inflammation and coagulation. An overview. Thrombosis Research 127(SUPPL. 2): S34-S37.

145. Tracy, R., and E. Bovill. 1995. Hemostasis and risk of ischemic disease: Epidemiologic evidence with emphasis on the elderly. Acute coronary care in the thrombolytic era. 2 nd ed, 27-43. St. Louis: Mosby Year Book.

146. Rauch, U., D. Bonderman, B. Bohrmann, J.J. Badimon, J. Himber, M.A. Riederer, and Y. Nemerson. 2000. Transfer of tissue factor from leukocytes to platelets is mediated by CD15 and tissue factor. Blood 96(1): $170-175$.

147. Levi, M., and T. Van Der Poll. 2010. Inflammation and coagulation. Critical Care Medicine 38(SUPPL. 2): S26-S34.

148. Esmon, C.T. 2005. The interactions between inflammation and coagulation. British Journal of Haematology 131(4): 417-430.

149. Bevers, E.M., P. Comfurius, D.W.C. Dekkers, M. Harmsma, and 
R.F.A. Zwaal. 1998. Transmembrane phospholipid distribution in blood cells: Control mechanisms and pathophysiological significance. Biological Chemistry 379(8-9): 973-986.

150. Sims, P.J., T. Wiedmer, C.T. Esmon, H.J. Weiss, and S.J. Shattil. 1989. Assembly of the platelet prothrombinase complex is linked to vesiculation of the platelet plasma membrane. Studies in Scott syndrome: An isolated defect in platelet procoagulant activity. Journal of Biological Chemistry 264(29): 17049-17057.

151. Conway, E.M., and R.D. Rosenberg. 1988. Tumor necrosis factor suppresses transcription of the thrombomodulin gene in endothelial cells. Molecular and Cellular Biology 8(12): 5588-5592.

152. Fukudome, K., and C.T. Esmon. 1994. Identification, cloning, and regulation of a novel endothelial cell protein C/activated protein $\mathrm{C}$ receptor. Journal of Biological Chemistry 269(42): 26486-26491.

153. Takano, S., S. Kimura, S. Ohdama, and N. Aoki. 1990. Plasma thrombomodulin in health and diseases. Blood 76(10): 2024-2029.

154. Østerud, B. 1998. Tissue factor expression by monocytes: Regulation and pathophysiological roles. Blood Coagulation and Fibrinolysis 9(SUPPL. 1): S9-S14.

155. Neumann, F.J., N. Marx, M. Gawaz, K. Brand, I. Ott, C. Rokitta, C. Sticherling, C. Meinl, A. May, and A. Schömig. 1997. Induction of cytokine expression in leukocytes by binding of thrombin-stimulated platelets. Circulation 95(10): 2387-2394.

156. Souter, P.J., S. Thomas, A.R. Hubbard, S. Poole, J. Römisch, and E. Gray. 2001. Antithrombin inhibits lipopolysaccharide-induced tissue factor and interleukin-6 production by mononuclear cells, human umbilical vein endothelial cells, and whole blood. Critical Care Medicine 29(1): 134-139.

157. Zwaal, R.F.A., and A.J. Schroit. 1997. Pathophysiologic implications of membrane phospholipid asymmetry in blood cells. Blood 89(4): $1121-1132$.

158. Levi, M., T. Van Der Poll, and H.R. Büller. 2004. Bidirectional 
relation between inflammation and coagulation. Circulation 109(22): 2698-2704.

159. Sturn, D.H., N.C. Kaneider, C. Feistritzer, A. Djanani, K. Fukudome, and C.J. Wiedermann. 2003. Expression and function of the endothelial protein C receptor in human neutrophils. Blood 102(4): 1499-1505.

160. Isobe, H., K. Okajima, M. Uchiba, A. Mizutani, N. Harada, A. Nagasaki, and K. Okabe. 2001. Activated protein C prevents endotoxininduced hypotension in rats by inhibiting excessive production of nitric oxide. Circulation 104(10): 1171-1175.

161. Cheng, T., D. Liu, J.H. Griffin, J.A. Fernández, F. Castellino, E.D. Rosen, K. Fukudome, and B.V. Zlokovic. 2003. Activated protein C blocks p53-mediated apoptosis in ischemic human brain endothelium and is neuroprotective. Nature Medicine 9(3): 338-342.

162. Joyce, D.E., L. Gelbert, A. Ciaccia, B. DeHoff, and B.W. Grinnell. 2001. Gene expression profile of antithrombotic protein $C$ defines new mechanisms modulating inflammation and apoptosis. Journal of Biological Chemistry 276(14): 11199-11203.

163. Oelschläger, C., J. Römisch, A. Staubitz, H. Stauss, B. Leithäuser, H. Tillmanns, and H. Hölschermann. 2002. Antithrombin III inhibits nuclear factor $\kappa \mathrm{B}$ activation in human monocytes and vascular endothelial cells. Blood 99(11): 4015-4020.

164. Yasui, H., E.C. Gabazza, S. Tamaki, T. Kobayashi, O. Hataji, H. Yuda, S. Shimizu, K. Suzuki, Y. Adachi, and O. Taguchi. 2001. Intratracheal administration of activated protein $\mathrm{C}$ inhibits bleomycininduced lung fibrosis in the mouse. American Journal of Respiratory and Critical Care Medicine 163(7): 1660-1668.

165. Okajima, K. 2001. Regulation of inflammatory responses by natural anticoagulants. Immunological Reviews 184: 258-274.

166. Thomas, R.H. 2001. Hypercoagulability syndromes. Archives of Internal Medicine 161(20): 2433-2439.

167. Chu, A.J. 2005. Tissue factor mediates inflammation. Archives of 
168. Denko, C.W., and M.W. Whitehouse. 1976. Experimental inflammation induced by naturally occurring microcrystalline calcium salts. The Journal of Rheumatology 3(1): 54-62.

169. Bach, R., and D.B. Rifkin. 1990. Expression of tissue factor procoagulant activity: Regulation by cytosolic calcium. Proceedings of the National Academy of Sciences 87(18): 6995-6999.

170. Palabrica, T., R. Lobb, B.C. Furie, M. Aronovitz, C. Benjamin, Y.-M. Hsu, S.A. Sajer, and B. Furie. 1992. Leukocyte accumulation promoting fibrin deposition is mediated in vivo by $\mathrm{P}$-selectin on adherent platelets. Nature 359: 848-851.

171. Lorant, D., M. Topham, R. Whatley, R. McEver, T. McIntyre, S. Prescott, and G. Zimmerman. 1993. Inflammatory roles of P-selectin. Journal of Clinical Investigation 92(2): 559.

172. Lorant, D.E., K.D. Patel, T.M. McIntyre, R.P. McEver, S.M. Prescott, and G.A. Zimmerman. 1991. Coexpression of GMP-140 and PAF by endothelium stimulated by histamine or thrombin: A juxtacrine system for adhesion and activation of neutrophils. The Journal of Cell Biology 115(1): 223-234.

173. Mikaelsson, M.E. (1991) The role of calcium in coagulation and anticoagulation. In Coagulation and blood transfusion, eds. Sibinga, C.T.S., Das, P.C., Mannucci, P.M., 26: 29-37. Developments in hematology and immunology. New York: Springer.

174. Pretorius, E. 2007. The role of platelet and fibrin ultrastructure in identifying disease patterns. Pathophysiology of Haemostasis and Thrombosis 36(5): 251-258.

175. Swanepoel, A.C., Lindeque, B.G., Swart, P.J., Abdool, Z., Pretorius, E. (2014) Estrogen causes ultrastructural changes of fibrin networks during the menstrual cycle: A qualitative investigation. Microscopy Research and Technique 77: 594-601.

176. Swanepoel, A.C., Pretorius E. (2015) Ultrastructural analysis of 
platelets during three phases of pregnancy: A qualitative and quantitative investigation. Hematology 20: 39-47.

177. Cooke, R.D. 1974. Calcium-induced dissociation of human plasma factor XIII and the appearance of catalytic activity. The Biochemical Journal 141: 683-691.

178. Kristiansen, G.K., and M.D. Andersen. 2011. Reversible activation of cellular factor XIII by calcium. Journal of Biological Chemistry 286(11): 9833-9839.

179. Nielsen, V.G., W.Q. Gurley Jr., and T.M. Burch. 2004. The impact of factor XIII on coagulation kinetics and clot strength determined by thrombelastography. Anesthesia and Analgesia 99(1): 120-123.

180. Nielsen, V.G., J.K. Kirklin, H. Hoogendoorn, T.C. Ellis, and W.L. Holman. 2007. Thrombelastographic method to quantify the contribution of factor XIII to coagulation kinetics. Blood Coagulation \& Fibrinolysis 18(2): $145-150$.

181. Pretorius, E., H.M. Oberholzer, W.J. Van Der Spuy, A.C. Swanepoel, and P. Soma. 2011. Qualitative scanning electron microscopy analysis of fibrin networks and platelet abnormalities in diabetes. Blood Coagulation and Fibrinolysis 22(6): 463-467.

182. Löbner, K., Füchtenbusch, M. (2004) Inflammation and diabetes. MMW Fortschritte der Medizin 146(35-36):32-3, 35-6.

183. Pretorius, E., A.C. Swanepoel, H.M. Oberholzer, W.J. Van Der Spuy, W. Duim, and P.F. Wessels. 2011. A descriptive investigation of the ultrastructure of fibrin networks in thrombo-embolic ischemic stroke. Journal of Thrombosis and Thrombolysis 31(4): 507-513.

184. Jin, R., G. Yang, and G. Li. 2010. Inflammatory mechanisms in ischemic stroke: role of inflammatory cells. Journal of Leukocyte Biology 87(5): 779-789.

185. Pretorius, E., H.M. Oberholzer, W.J. Van Der Spuy, A.C. Swanepoel, and P. Soma. 2012. Scanning electron microscopy of fibrin networks in rheumatoid arthritis: A qualitative analysis. Rheumatology International 
186. Gasparyan, A.Y., L. Ayvazyan, E. Pretorius, and G.D. Kitas. 2014. Platelets in rheumatic diseases: Friend or foe? Current Pharmaceutical Design 20(4): 552-566.

187. Epstein, F.H., E.H. Choy, and G.S. Panayi. 2001. Cytokine pathways and joint inflammation in rheumatoid arthritis. New England Journal of Medicine 344(12): 907-916.

188. Pretorius, E., J. Bester, N. Vermeulen, B. Lipinski, G.S. Gericke, and D.B. Kell. 2014. Profound morphological changes in the erythrocytes and fibrin networks of patients with hemochromatosis or with hyperferritinemia, and their normalization by iron chelators and other agents. PLoS ONE 9(1): e85271.

189. Wang, L., E.E. Johnson, H.N. Shi, W.A. Walker, M. WesslingResnick, and B.J. Cherayil. 2008. Attenuated inflammatory responses in hemochromatosis reveal a role for iron in the regulation of macrophage cytokine translation. The Journal of Immunology 181(4): 2723-2731.

190. Pretorius, E. 2012. Ultrastructural changes in platelet membranes due to cigarette smoking. Ultrastructural Pathology 36(4): 239-243.

191. Pretorius, E., H.M. Oberholzer, W.J. Van Der Spuy, and J.H. Meiring. 2010. Smoking and coagulation: The sticky fibrin phenomenon. Ultrastructural Pathology 34(4): 236-239.

192. De Maat, M.P.M., and C. Kluft. 2002. The association between inflammation markers, coronary artery disease and smoking. Vascular Pharmacology 39(3): 137-139.

193. Malerba, M., and P. Montuschi. 2012. Non-invasive biomarkers of lung inflammation in smoking subjects. Current Medicinal Chemistry 19(2): 187-196.

194. Van Der Vaart, H., D.S. Postma, W. Timens, and N.H.T. Ten Hacken. 2004. Acute effects of cigarette smoke on inflammation and oxidative stress: A review. Thorax 59(8): 713-721. 
195. Pretorius, E., du Plooy, J., Soma, P., Gasparyan, AY. (2014) An ultrastructural analysis of platelets, erythrocytes, white blood cells, and fibrin network in systemic lupus erythematosus. Rheumatology International 34: 1005-1009.

196. Belmont, H.M., S.B. Abramson, and J.T. Lie. 1996. Pathology and pathogenesis of vascular injury in systemic lupus erythematosus Interactions of inflammatory cells and activated endothelium. Arthritis and Rheumatism 39(1): 9-22.

197. Pretorius, E., and H.M. Oberholzer. 2009. Ultrastructural changes of platelets and fibrin networks in human asthma: A qualitative case study. Blood Coagulation and Fibrinolysis 20(2): 146-149.

198. Kay, A.B.. 1991. Asthma and inflammation. Journal of Allergy and Clinical Immunology 87(5): 893-910. 